\title{
3-2015
}

\section{The Affective and Interpersonal Consequences of Obesity}

Emma E. Levine

University of Pennsylvania

Maurice E. Schweitzer

University of Pennsylvania

Follow this and additional works at: https://repository.upenn.edu/fnce_papers

Part of the Finance and Financial Management Commons, and the Social and Behavioral Sciences Commons

\section{Recommended Citation}

Levine, E. E., \& Schweitzer, M. E. (2015). The Affective and Interpersonal Consequences of Obesity. Organizational Behavior and Human Decision Processes, 127 66-84. http://dx.doi.org/10.1016/ j.obhdp.2015.01.002 


\title{
The Affective and Interpersonal Consequences of Obesity
}

\begin{abstract}
The incidence of obesity in the United States has tripled over the past fifty years, posing significant challenges for organizations. We build on stereotype content research and offer an overarching framework to understand individuals' affective, cognitive, and behavioral responses to obesity. Across five studies, we demonstrate that individuals associate obesity with perceptions of low competence. Perceptions of low competence predict affective (disgust, sympathy) and behavioral (low help, high harm) responses to obesity. Consistent with the BIAS Map (Cuddy, Fiske, \& Glick, 2007), these discriminatory responses are moderated by perceptions of warmth. We demonstrate that, in some cases, shifting perceptions of warmth is just as effective as losing weight for curtailing discrimination towards the obese. Our findings demonstrate that social categorization is labile and we offer prescriptive advice for individuals seeking to change the way others perceive them.
\end{abstract}

\section{Keywords}

social cognition, interpersonal affect, obesity, stereotypes

Disciplines

Finance and Financial Management | Social and Behavioral Sciences 


\title{
The Affective and Interpersonal Consequences of Obesity
}

\author{
Emma E. Levine \\ JMHH 533.6, 3730 Walnut Street \\ The Wharton School \\ University of Pennsylvania \\ Philadelphia, PA 19104, United States \\ Email: emmased@wharton.upenn.edu
}

Maurice E. Schweitzer

JMHH 544, 3730 Walnut Street

The Wharton School

University of Pennsylvania

Philadelphia, PA 19104, United States

Email: schweitz@wharton.upenn.edu

Forthcoming in Organizational Behavior and Human Decision Processes

Acknowledgements:

The authors thank the members of the Wharton Decision Processes lab for their helpful comments. We are grateful for the support of the Wharton Behavioral Lab and the Russell Ackoff Fellowship of the Wharton Risk Management and Decision Processes Center. 


\title{
The Affective and Interpersonal Consequences of Obesity
}

\begin{abstract}
The incidence of obesity in the United States has tripled over the past fifty years, posing significant challenges for organizations. We build on stereotype content research and offer an overarching framework to understand individuals’ affective, cognitive, and behavioral responses to obesity. Across five studies, we demonstrate that individuals associate obesity with perceptions of low competence. Perceptions of low competence predict affective (disgust, sympathy) and behavioral (low help, high harm) responses to obesity. Consistent with the BIAS Map (Cuddy, Fiske, \& Glick, 2007), these discriminatory responses are moderated by perceptions of warmth. We demonstrate that, in some cases, shifting perceptions of warmth is just as effective as losing weight for curtailing discrimination towards the obese. Our findings demonstrate that social categorization is labile and we offer prescriptive advice for individuals seeking to change the way others perceive them.
\end{abstract}

Words: 137

Keywords: social cognition, interpersonal affect, obesity, stereotypes 
Introduction

Look, I'm sorry, but New Jersey Governor Chris Christie cannot be president: He is just too fat. Maybe, if he runs for president and we get to know him, we will overlook this awkward issue...But we shouldn't overlook it -- unless he goes on a diet and shows he can stick to it.

-Michael Kinsley (2012), Bloomberg.com

The rate of obesity in the United States has tripled over the past fifty years, and has risen dramatically around the globe. Sixty-eight percent of Americans are overweight and 30\% are obese (Flegal, Carroll, Ogden, \& Curin, 2010). ${ }^{1}$ The serious health consequences of the obesity epidemic are well documented (Cawley \& Meyerhoefer, 2012; Quesenberry, Caan, \& Jacobson, 1998).

In addition to placing a strain on the United States health care system, growing rates of obesity present a challenge for organizations. Obesity is associated with increased employee absenteeism and decreased effectiveness (Finkelstein, Ruhm, \& Kosa, 2005), and obese employees earn less than non-obese employees (Baum \& Ford, 2004; Judge \& Cable, 2011). Obesity also imposes significant interpersonal costs. Obesity influences how individuals are perceived and treated within organizations.

Despite growing national concern with obesity, significant gaps remain with respect to our understanding of individuals’ affective and cognitive reactions to obesity. Scholars have documented the prevalence of weight-based discrimination, but we know less about when and

\footnotetext{
${ }^{1}$ The World Health Organization defines an overweight individual as someone with a Body Mass Index (BMI) between 25 and 29.9, and defines an obese individual as someone with a BMI of 30 or higher. (Flegal et al., 2010).
} 
why this occurs. In this paper, we focus on the mechanisms linking obesity with discrimination, answering the call of prior researchers (e.g., Roehling, 1999).

In contrast to prior work that has conceptualized attitudes towards obesity as generalized antipathy, we build a richer theoretical and empirical understanding of how obesity influences social cognition. We study obesity with respect to the Stereotype Content Model, which proposes that individuals are evaluated along two fundamental dimensions: warmth and competence. Across five experiments, we document a robust relationship between obesity and perceptions of low competence and we describe how perceptions of warmth moderate cognitive and affective reactions to obese individuals. We demonstrate that interpersonal reactions to obese individuals are more nuanced than prior work has assumed, and we break new ground by identifying the specific mechanisms that link obesity with harming and helping behaviors. We find that obesity exerts greater influence over perceptions of competence than warmth, and we find that much of the relationship between obesity and discrimination is derived from two sources: perceptions of competence and feelings of disgust.

We also investigate strategies for shifting perceptions of and curtailing discrimination towards the obese. Specifically, we explore how physical signals (weight loss) and social signals (demonstrating warmth) influence responses to obesity. We document substantial benefits from displays of warmth. We find that signaling warmth can curtail stigma associated with low competence, and that this may be more effective for shifting interpersonal perceptions than actually losing weight. Broadly, our findings demonstrate that discrimination rooted in biased perceptions of one dimension of social cognition (e.g., competence) can be influenced by shifts in the non-focal dimension of social cognition (e.g. warmth). Our findings inform prescriptive 
advice for obese and other stigmatized individuals who could benefit from shifting their social categorization.

\section{Stereotypes, Obesity, and the BIAS Map}

Much of the prejudice we observe in the workplace derives from social category comparisons and in-group favoritism (Brewer, 1979; Tajfel \& Turner, 1979). By generating negative impressions of dissimilar others, individuals create a positive comparative identity of their in-group. Much of the research on social categorization suggests that social exchange between diverse groups can mitigate stigma and promote cooperation (Allport, 1954; see Dovidio, Gaertner, \& Kawakami, 2003).

Although research on social categorization has considered many individual characteristics that influence interpersonal perception and behavior, including profession, race, age, culture, religion, and even university or political party affiliation (e.g; Chen \& Kenrick, 2002; Cuddy, Norton, \& Fiske, 2005, Cuddy, Fiske, \& Glick, 2007; Jehn, Northcraft, \& Neale, 1999; Loyd, Wang, Phillips, \& Lount, 2013; Rosette, Leonardelli, \& Phillips, 2008), a conspicuous attribute of physical appearance has been absent from this research: obesity. Organizational research on stereotypes and diversity has been surprisingly silent with respect to weight.

Weight-based discrimination may be relatively underexplored because it is fundamentally different from other types of discrimination. Unlike other sources of stigma, such as race or ethnicity, weight is perceived to be malleable and group membership is seen as unstable. Given the growing rates of obesity in the U.S. workplace, it is also unlikely that a lack of exposure drives discriminatory behavior towards the obese. In addition, unlike race or ethnicity, many people perceive obesity to reflect a choice (e.g., Quinn \& Crocker, 1999). For these reasons, we 
approach weight-based discrimination differently than prior research that has conceptualized stigma as the product of social categorization (Brewer, 1979; Tajfel \& Turner, 1979), social ideologies (e.g. Sidanius, Pratto, Van Laar, \& Levin, 2004), uni-dimensional disliking (e.g. Allport, 1954; Tajfel, 1981), or the result of specific biases (e.g. Crandall, 1994; Teachman, Gapinski, Brownell, Rawlins, \& Jeyaram, 2003). Rather than conceptualizing weight-based stigma as the product of group membership and intergroup relationships, we develop our hypotheses with respect to the Stereotype Content Model (SCM) and the Behavior from Intergroup Affect and Stereotypes (BIAS) framework (Cuddy et al., 2007; Fiske, Cuddy, Glick, $\& \mathrm{Xu}, 2002)$.

The SCM and the BIAS Map. The SCM characterizes individuals along two fundamental dimensions of social cognition: warmth and competence. According to the SCM, warmth and competence are universal dimensions that are critical to intergroup functioning. Warmth judgments are essential because individuals must anticipate others’ intentions towards them and determine who is friend and who is foe. Warmth is operationalized by judgments of how "kind" or "good-natured" a target is.

Individuals also need to assess the extent to which others are able to accomplish their goals. In other words, individuals judge whether others are competent enough to enact help or harm. Competence is operationalized by judgments of how "able," "intelligent,” and "confident” a target is. Perceptions of warmth and competence influence perceptions of individuals and groups across domains and nationalities (e.g., Clausell \& Fiske, 2005; Eckes, 2002; Glick \& Fiske, 1996; Wojciszke \& Klusek, 1996).

Within the SCM, perceptions of warmth and competence interact to predict cognitive, affective, and behavioral responses towards a target. Importantly, these cognitive responses can 
be both positive and negative. That is, the SCM conceptualizes stigma not simply as unidimensional disliking, but rather as the product of two orthogonal dimensions. Individuals and groups can fall into four possible perceptual categories: High Warmth-High Competence, Low Warmth-High Competence, High Warmth-Low Competence, or Low Warmth-Low Competence.

The BIAS (Behaviors from Intergroup Affect and Stereotypes) Map builds on the SCM and proposes that each possible combination of warmth and competence - each "quadrant" on the BIAS Map - elicits a unique set of affective and behavioral responses (Cuddy et al., 2007). Specifically, High Warmth-High Competence individuals elicit upward affiliative emotions, such as admiration. These emotions reflect personal attributions for positive outcomes. Low WarmthHigh Competence individuals elicit upward contrastive emotions, such as jealousy or envy, which reflect situational attributions for positive outcomes. High Warmth-Low Competence individuals elicit downward affiliate emotions, such as pity and sympathy, which reflect situational attributions for negative outcomes. Lastly, Low Warmth-Low Competence individuals elicit downward, contrastive emotions, such as anger, contempt and disgust, which reflect dispositional attributions for negative outcomes. For example, the elderly are typically perceived to be warm and incompetent (High Warmth-Low Competence); and within this framework, the elderly elicit sympathy. This emotion is consistent with the perception that the elderly are not responsible for their lack of competence. An important tenant of the BIAS Map is that emotions predict behavior better than does cognition. For example, the degree to which incompetent targets elicit harm will depend on the relative sympathy and contempt they elicit.

The BIAS Map also proposes that warmth and competence predict different types of behavioral responses. Specifically, perceptions of warmth predict active behaviors, whereas perceptions of competence predict passive behaviors. The active-passive distinction reflects 
differences in intensity and direction. Because perceptions of warmth pertain to a target’s perceived intentions, perceptions of warmth predict active and effortful behaviors. Perceptions of high warmth predict intentions to help and assist, whereas perceptions of low warmth predict intentions to harm and sabotage. Perceptions of competence are a secondary concern because they relate to capability, rather than intentions. Within the BIAS Map, perceptions of competence elicit passive behaviors. Perceptions of high competence predict cooperation, whereas perceptions of low competence predict neglect. Taken together, it is perceptions of both warmth and competence that predict unique sets of interpersonal behaviors. For example, the elderly (High Warmth-Low Competence) are met with both active help and passive harm; they are sometimes actively assisted, and sometimes neglected.

Although the SCM and the BIAS Map have primarily been used to explain stable affective and behavioral reactions to stereotyped groups, related research has demonstrated that these reactions are labile. By shifting perceptions of warmth and competence, individuals can change their social categorization. For example, when professional women have children, they may gain warmth and lose competence (Cuddy, Fiske, \& Glick, 2004).

Scholars have used the SCM and the BIAS Map to study perceptions of a large number of different groups, such as the elderly, the poor, feminists, the disabled, Jews, Asians, Christians, and African Americans. Surprisingly, prior SCM and BIAS Map research has ignored a large and growing group characterized by one of the most salient aspects of physical appearance: weight.

We review extant research on obesity and discrimination to build our thesis: obesity is perceived as a signal of low competence. By situating obesity within the BIAS Map, we offer an overarching framework to understand and predict both positive and negative affective, cognitive, and behavioral responses to obesity. 


\section{Obesity and Discrimination}

Obese individuals face discrimination across many stages of their careers. Compared to individuals who are not overweight, overweight individuals are less likely to be hired (Pingitore, et al., 1994), less likely to be recommended (Larkin \& Pines, 1979), less likely to be assigned desirable job responsibilities (e.g., Bellizzi \& Hasty, 1998) and less likely to be promoted (Rothblum, Brand, Miller, \& Oetjen, 1990). In addition, when overweight employees perform the same jobs as non-overweight employees, they face a host of negative interpersonal behaviors. Obese individuals are more likely to be the targets of pejorative jokes and comments, (Puhl \& Brownell, 2006), more likely to face severe disciplinary decisions (Roehling, 1999), less likely to receive high-quality training (Shapiro, King, \& Quinones, 2007) and ultimately earn lower wages (Baum \& Ford, 2004; Judge \& Cable, 2011).

Surprisingly, little prior research has considered the affective or cognitive mechanisms that link obesity with interpersonal outcomes (Pingitore et al., 1994; Roehling, 1999). As a result, our understanding of the interpersonal consequences of obesity is limited. Our work offers insight into the specific cognitions associated with obesity - specifically, low competence - and explains how emotional responses and perceptions of competence interact to predict helping and harming behaviors.

\section{Cognitive biases towards the obese}

Prior research demonstrates that obese individuals are perceived to be deficient in many desirable traits (Greenberg, Eastin, Hofschire, Lachlan, \& Brownell, 2003; Roehling, 1999). Compared to non-obese individuals, obese individuals are perceived to be less moral (Allon, 1982; Cahnman, 1968), less trustworthy (McKee \& Smouse, 1983), and less conscientious and agreeable (Roehling, 1999). People also perceive obese individuals to be less motivated and 
intelligent than non-obese individuals (Larkin \& Pines, 1979; Larwood \& Gattiker, 1985; Puhl \& Brownell, 2012). These findings suggest that obesity influences both warmth-related (moral, trustworthy) and competence-related (motivation, intelligence) traits.

However, a closer look at the source of weight-based stigma suggests that anti-obesity bias primarily relates to the domain of competence. Scholars have suggested that weight-based stigma persists because, unlike individuals in many other stigmatized groups, obese individuals are perceived to be personally responsible for their condition (e.g., Crandall, 1994; Quinn \& Crocker, 1999; Vartanian, 2010; Weiner, Perry, \& Magnusson, 1988). People tend to attribute obesity to a lack of self-control and motivation, rather than recognizing that it is largely determined by genetics, unlike most other physical traits (e.g. Puhl \& Brownell, 2006; Puhl \& Brownell, 2012). In other words, many people view obesity as a choice.

Although scholars have discussed the importance of perceptions of control in determining reactions to obesity, much of this research still conceptualizes weight-based stigma as general disliking (Crandall, 1994). In contrast, we argue that weight-based stigma is rooted in perceptions of low competence. Consistent with Fiske et al. (2002), we define competence as general capability. If people believe that obese individuals lack self-control, the ability to exercise restraint and focus on long-term and short-term goals, then they are likely to believe that, compared to non-obese individuals, obese individuals are simply less able to do what is required of them. This suggests:

Hypothesis 1: Obesity is perceived to be a signal of low competence.

Building on this prediction, and the BIAS Map, we expect that obese individuals can be categorized into two possible perceptual quadrants, High Warmth-Low Competence, or Low 
Warmth-Low Competence, and will elicit the emotions and behaviors consistent with these quadrants.

\section{Affective Reactions to Obesity}

According to the SCM and the BIAS Map, perceptions of low competence elicit downward, contrastive emotions such as disgust, contempt, and anger. Consistent with this prediction, scholars have demonstrated that obesity evokes disgust (e.g. Vartanian, 2010). Disgust is characterized by the desire to move away from or expel a stimulus (Rozin, Haidt, \& McCauley, 1993).

Obesity elicits disgust for two reasons. First, obesity is perceived to be visually displeasing (Crocker, Cornwell, \& Major, 1993; Goffman, 1963). Just as one might look away and be repelled by the sight of an open wound, obesity is perceived to be unattractive and can elicit aversive reactions that cause people to look away from or distance themselves from obese individuals. Second, obesity elicits moral disgust. The "choice” to be obese violates the Protestant work ethic and social norms for self-control (Allon, 1982; Goffman, 1963; Quinn \& Crocker, 1999). Violating these values can evoke moral disgust, particularly among those who hold these values in high esteem. These findings are consistent with the BIAS Map, which suggests that groups and individuals who are perceived to be personally responsible for negative outcomes elicit disgust.

However, according to the BIAS Map, targets that are perceived to lack competence also elicit affiliative downward emotions, such as sympathy. Little work has examined when - if ever - obesity elicits sympathy. Consistent with the SCM and the BIAS Map, we propose:

Hypothesis 2: Obese individuals elicit more disgust and more sympathy than non-obese individuals. 


\section{Behavioral responses to obesity}

According to the BIAS MAP, low competence groups elicit greater passive harm, and less passive help than high competence groups. Passive behaviors, in contrast to active behaviors, are less effortful and are often not directed toward the target. For example, excluding someone from a group is a type of passive harm. Consistent with this proposition, prior work has found that obese individuals are more likely to be ignored in customer service interactions (King, Shapiro, Hebl, Singletary, \& Turner, 2006) and neglected (Weiner et al., 1988). Integrating these findings with the predictions of the BIAS Map, we postulate:

Hypothesis 3: Obese individuals elicit more passive harm and less passive help than nonobese individuals.

\section{Curtailing discrimination towards the obese}

The BIAS Map framework informs strategies to curtail the harmful affective and behavioral responses to obesity. In this work, we investigate two strategies: physical change (weight loss) and social signaling (demonstrating warmth). The first strategy reflects a shift in the source of stigma - weight itself. The second strategy reflects a shift in the orthogonal dimension of social cognition - warmth. By examining these two strategies, we gain insight not only into prescriptions for curbing discrimination, but also perceptions of warmth and competence, and how these two perceptions interact to predict behavioral reactions to the obese.

Almost no prior work has investigated how people perceive individuals who have lost weight (see Fee \& Nusbaumer, 2012 for an exception). We expect that losing weight will signal self-control, re-establish perceptions of competence, and consequently, mitigate biases associated with obesity. Specifically, we propose: 
Hypothesis 4: Weight loss will increase perceptions of competence, lower disgust, decrease passive harm, and increase passive help towards the obese.

Although weight loss may mitigate the primary bias associated with obesity (low competence), signaling warmth may also have a number of beneficial interpersonal consequences. Shifting perceptions of the obese from the Low Warmth-Low Competence quadrant to the High Warmth-Low Competence is likely to increase active help. Whereas losing weight may increase passive cooperation, signaling warmth may increase direct assistance. Furthermore, high warmth is associated with low disgust and high sympathy. Consistent with the SCM and the BIS Map, we predict:

Hypothesis 5: Warmth will increase sympathy, lower disgust, and increase active help towards the obese.

---- Figure 1 about here ---

We summarize these predictions in Figure 1. We test these predictions across one pilot study and five experiments. These studies make three central contributions to our understanding of obesity and discrimination. First, we develop a parsimonious framework for understanding a broad range of interpersonal consequences of obesity. We demonstrate that competence is the primary dimension of social cognition associated with obesity, and we position this finding within a coherent framework to understand the full range of interpersonal consequences of obesity.

Second, we provide evidence of the primacy of affective over cognitive mechanisms in predicting behavior. Scholars have called for future research to examine the mechanisms linking obesity with harm, rather than focusing on harm as the outcome of interest (Roehling, 1999). We 
address this gap in our understanding. We explore the affective ambivalence that obesity evokes, and describe how sympathy and disgust influence helping and harming behaviors.

Third, we explore novel strategies to mitigate stigma. Prior research has focused on the role of perceived control in shaping perceptions of obesity (e.g., Crandall, 1994). In contrast, we investigate the role of physical change (e.g., weight loss) and social signaling (e.g., demonstrating warmth). We demonstrate that individuals can shift their social categorization not only by overcoming the primary bias (e.g. low competence), but also by signaling the non-focal dimension (e.g., warmth).

\section{Pilot Study}

We motivate our investigation with a pilot study. This pilot study demonstrates that obesity shifts perceptions of competence, but not warmth. In order to isolate cognitive, rather than visceral responses to obesity, we merely presented participants with text that listed a job candidate’s weight (in pounds).

\section{Method}

Participants. We recruited one hundred fifty-two American adults (66 women, 84 men, 2 missing responses; $M_{\text {age }}=33$ years, $S D=11.4 ; M_{\text {work experience }}=13$ years, $S D=10.6$ ) to participate in this study through Amazon Mechanical Turk.

Design. We randomly assigned participants to one of four experimental conditions from a 2(Weight: obese vs. non-obese) x 2(Gender) between-subjects design.

Procedure and materials. We told participants that they would evaluate a potential job candidate, based on the first page of his/her job application. Participants read information that one (fictitious) job candidate had submitted online, which included information about the candidate's height, weight, age, and race. We described female and male candidates as having 
mean height in the United States (Ogden, Fryar, Carroll, \& Flegal, 2004). Female candidates were 5 feet 4 inches; male candidates were 5 feet 9 inches. All candidates were "White" and age 25.

Obesity manipulation. The weight values we used for our manipulations were based on the $50^{\text {th }}$ and $95^{\text {th }}$ percentile for weight of males and females in the United States (according to the National Health and Nutrition Examination Survey, provided by the Center for Disease Control and Prevention; http://www.cdc.gov/nchs/nhanes/nh3data.htm). For 5 feet 4 inch tall females, the weight we listed was 132 pounds in the non-obese condition and 220 pounds in the obese condition. For 5 feet 9 inch tall male targets, the weight we listed was 168 pounds in the nonobese condition and 243 pounds in the obese condition. We provide an example of our stimulus in Appendix A.

Dependent variables. Each participant rated the job candidate on warmth and competence. To curtail social desirability concerns, we employed indirect measures (see Fisher, 1993); we asked participants to consider how peers and potential coworkers would rate the candidate.

Participants judged the candidate’s warmth using four items: sincere, good natured, warm, and tolerant, ( $\alpha=$.92; e.g., Fiske et al., 2002; Rudman \& Glick, 1999). Participants judged the candidate’s competence using five-items: competent, intelligent, confident, competitive, and independent, ( $\alpha=$.89; Cuddy et al., 2007).

Participants also rated the candidate’s weight using two items: overweight and thin (reverse scored) $(r=.63, p<.001)$. We used 7-point Likert scales anchored at $1=$ "Not at all” and 7 = “Extremely” for all judgments.

After participants submitted their responses, they answered demographic questions. 


\section{Results}

We conducted a 2(Weight) x 2(Gender) ANOVA on all dependent measures. Across our studies, we did not drop any participants from any analyses and we report all measures we collected.

Manipulation check. Participants rated candidates in the obese condition as significantly more overweight $(M=5.81, S D=0.96)$ than candidates in the non-obese condition $(M=3.35$, $S D=1.06), F(1,148)=230.40, p<.01, \eta_{p}^{2}=.61$. We did not find a significant main effect of Gender, nor did we find a significant Gender x Weight interaction.

Competence. Supporting our thesis, participants rated obese candidates as significantly less competent $(M=4.11, S D=0.90)$ than non-obese candidates $(M=4.97, S D=0.77), F(1$, 148) $=40.92, p<.01, \eta_{p}^{2}=.21$.

We found no main effect of Gender. However, we did find a significant Gender x Weight interaction, $F(1,148)=9.72, p<.01, \eta_{p}^{2}=.06$. The obesity manipulation had a greater effect on females' perceived competence $\left(M_{\text {obese }}=4.03, S D_{\text {obese }}=0.88\right.$ vs. $M_{\text {non-obese }}=5.28, S D_{\text {non-obese }}=$ $0.69) ; t(76)=6.79, p<.01$, than males' perceived competence $\left(M_{\text {obese }}=4.19, S D_{\text {obese }}=0.92\right.$ vs. $\left.M_{\text {non-obese }}=4.63, S D_{\text {non-obese }}=0.71\right) t(74)=2.30, p=.02$, although both simple effects were significant. This unanticipated interaction appears to be driven by perceptions of the non-obese female, who was rated as particularly competent. Importantly, obesity reduced perceptions of competence for both males and females.

Warmth. We found no effect of obesity on warmth, $\left(M_{\text {obese }}=4.63, S D_{\text {obese }}=1.03 \mathrm{vs}\right.$. $\left.M_{\text {non-obese }}=4.81, S D_{\text {non-obese }}=0.78\right), F(1,148)=1.27, p=.26, \eta_{p}^{2}=.008$. We found a main effect of Gender, $\left.F(1,148)=.79, p=.38, \eta_{p}^{2}=.005\right)$, such that females $(M=4.90, S D=0.86)$ were 
perceived to be warmer than males $(M=4.53, S D=0.95)$, consistent with existing research on gender stereotypes. We did not find a significant Gender x Weight interaction. ${ }^{2}$

\section{Discussion}

Although prior research suggests that obese individuals are perceived to lack a number of desirable traits, our pilot study demonstrates that obesity primarily affects perceptions of competence, rather than warmth, supporting Hypothesis 1. In our next studies, we examine the consequences of this association.

\section{Study 1}

In Study 1, we explore how the association between obesity and competence influences predicted performance. We collected data from 100 games of Jeopardy! played between 2005 and 2012 and incentivized participants to judge contestants’ performance. Jeopardy! reflects a domain in which performance is purely knowledge-based, and independent of social perception. In this study, we demonstrate that contestants’ weight influences expected performance, but not actual performance.

\section{Procedure and Materials}

We recruited two hundred two American adults (98 women, 104 men; $M_{\text {age }}=34$ years, $S D=10.9, M_{\text {work experience }}=14$ years, $\left.S D=11.1\right)$ to participate in this study through Amazon Mechanical Turk.

We asked each participant to predict the winner of 10 different games of Jeopardy!. For each game in which participants correctly chose the winner, they received a small bonus

\footnotetext{
${ }^{2}$ We also directly compared the effects of obesity on competence and warmth by running a mixed ANOVA. We entered weight as the between-subject factor and judgment-type (competence vs. warmth) as a within subject factor. We find that the interaction between weight and judgment -type is significant $(F(1,150)=43.85, p<.001)$, suggesting that obesity has a qualitatively different effect on warmth and competence.
} 
payment (\$.10/game). Participants reviewed the rules of Jeopardy!, saw photographs of the three contestants who played each game, and then guessed the winner of the game.

\section{Jeopardy! dataset}

Jeopardy! is a popular U.S. game show that features trivia across a wide variety of topics, including history, language, literature, the arts, the sciences, and geography. Jeopardy! has been on television since 1984, and has over 25 million viewers each week (http://www.jeopardy.com/showguide/abouttheshow/showhistory/). In each game of Jeopardy!, three contestants compete by answering trivia questions. Contestants accumulate money by answering questions correctly and the contestant with the most money at the end of each episode keeps his or her earnings. The winner at the end of each episode also gets to compete in the next episode against two new contestants.

We collected contestants’ photographs and performance statistics from Jeopardy!'s archival website (http://www.jarchive.com). We included the most recent 100 games of Jeopardy! for which an official Jeopardy! photograph was available for each of the three contestants. This resulted in a sample of 100 games that were played between 2005 and 2012, featuring 158 unique contestants. All materials are available from the authors upon request.

Rating Contestant Weight. We had two independent raters assess the weight and physical attractiveness of the 158 contestants. Raters assessed contestants’ weight using a 9-point Body Mass Index $(\mathrm{BMI})$ scale (inter-rater correlation $=.81$ ). This scale, depicted in Figure 2, provides accurate illustrations of body type for each BMI category and has been validated in prior research (e.g., Bulik et al., 2001). The mean weight rating of the Jeopardy! contestants in our data set was 4.58 , and the standard deviation was 1.04 . 
Rating Contestant Attractiveness. The same two independent raters also assessed contestants' physical attractiveness $(1=$ "Not at all attractive” and $9=$ "Extremely attractive;” inter-rater correlation $=.61$ ). The mean attractiveness rating of the Jeopardy! contestants in our data set was 4.43, and the standard deviation was 1.06 .

For both weight and physical attractiveness ratings, we averaged the two raters' scores for each dimension to create overall measures of Contestant Weight and Contestant Attractiveness.

Dependent variables. In the main study, participants first reviewed the rules of Jeopardy!. Then, participants predicted the winner of 10 different games of Jeopardy!. For each game, participants viewed the photographs of the three contestants who actually competed against one another in that game of Jeopardy! We asked participants to guess which contestant won the game. Participants had no additional information. Therefore, for every contestant in every game that a participant viewed (100 games x 3 contestants/game), we had a dichotomous measure that captured predicted performance; $1=$ predicted to win and $0=$ predicted to lose.

Competence. After participants chose the winner of each game, they rated the competence of each of the three contestants using the same scale we used in the pilot study.

Each participant predicted the winner of 10 different games. Because some contestants were involved in multiple games, some participants judged the same contestant twice.

Participants answered demographic questions about themselves after judging the 10 games. We followed up with participants the following day to provide their bonus payments.

\section{Results}

We conducted our main analyses at the contestant-game level $(N=300)$. We created an average Perceived Competence rating and an average Predicted Likelihood of Wining rating for 
each of the 300 contestant-game observations. Each contestant in each Jeopardy! game was judged by at least 18 of the 202 participants.

That is, for each of the 300 unique contestant-game observations (100 games x 3 players/game), we generated a single Perceived Competence rating, which we calculated by averaging the competence ratings across all the participants who viewed each contestant within a particular game. Similarly, for each of the 300 contestant-game observations, we generated an average Predicted Likelihood of Winning measure, which we calculated as the number of times the contestant was predicted to win the game, divided by the total number of times the game was viewed by participants. The data set we used for the remainder of our main analyses included Perceived Competence, Predicted Likelihood of Winning, Contestant Gender, Actual Outcome (whether the contestant actually won or lost the game), Contestant Weight, and Contestant Attractiveness.

Because contestants were nested within games and some contestants appear in the data set multiple times (due to winning streaks), we cluster standard errors at both the game level and the contestant level in our regression analyses. We report these regressions results in Table 1.

Preliminary analyses. Contestant weight did not influence actual Jeopardy! outcomes. Using logistic regression, we found no significant effect of contestant weight on actual performance $\left(b=-0.03, p=.74\right.$, Psuedo- $\left.R^{2}<.001\right)$. A linear regression also supports this result ( $\left.b=-0.007, p=.75, R^{2}<.001\right)$. This finding serves as our benchmark. Any significant negative relationship between contestant weight and participants’ predicted performance reflects a bias in this context, rather than rational statistical discrimination.

\section{Main analyses}


Predicted Likelihood of Winning. Contestant weight did influence predicted Jeopardy! performance. Using linear regression, we found a significant effect of contestant weight on the average predicted likelihood of winning a game $\left(b=-0.030, p=.008, R^{2}=.04\right)$. Each one-point increase in a contestant's weight rating (on the nine-point scale depicted in Figure 2) was associated with a 3.0\% decrease in the contestant's average predicted likelihood of winning a game. This effect was significant and stable, even after controlling for contestant gender, attractiveness, and actual performance. We report these regression results in Table 1 . We plot the relationship between weight and predicted performance, and the relationship between weight and actual performance in Figure 2. ${ }^{3}$

--- Figure 2 and Table 1 about here ---

Competence. Supporting our thesis, contestant weight influenced perceived competence $\left(b=-0.090, t(297)=4.70, p<.001, R^{2}=.19\right)$. That is, as weight increased, perceived competence decreased.

Mediation analysis. We conducted a bootstrap analysis with 10,000 samples to test whether or not perceived competence mediates the relationship between contestant weight and predicted performance (MacKinnon, Fairchild, \& Fritz, 2007). We found a significant indirect effect for competence (Indirect Effect $=-.03, S E=.00 ; 95 \% C I=[-.042,-.019]$ ). Specifically, we found that as weight increased, perceived competence decreased ( $a=-.095, p<.01)$, and as

\footnotetext{
${ }^{3}$ We conducted our main analyses at the contestant-game level. As a robustness check, we also conducted a logistic regression at the participant-prediction level. In the logistic regression, each participant's prediction of the performance of each contestant in each game was our unit of analysis and predicted performance was the binary dependent variable $(0=$ predicted to lose, $1=$ predicted to win $)$. In this set of analyses, we clustered standard errors at the participant level and the game level, and controlled for the same variables we controlled for in the main analyses (gender, gender $\mathrm{x}$ weight interaction, physical attractiveness, and actual performance). These analyses yielded convergent results; we find a significant negative effect of weight on predicted performance; $b=-0.149, p<.001$. This effect also remains significant after including participant fixed effects; $b=-0.155, p<.001$.
} 
perceived competence decreased, so did predicted performance $(b=0.32, p<.001)$. Once we included competence in our model, the relationship between weight and predicted performance became insignificant $\left(c=-0.03, p<.01 ; c^{\prime}=0.0006, p=.95\right)$, suggesting full mediation.

\section{Discussion}

Obesity influences perceptions of competence, even when individuals are incentivized to provide accurate judgments. In Study 1, contestant weight significantly influenced expected performance in Jeopardy! games, even after controlling for contestant gender, attractiveness, and actual performance. In this study, the association between weight and perceived competence reflects systematic bias; individuals were less willing to bet on obese targets’ performance, even though no actual relationship between obesity and performance exists in this setting.

Jeopardy! is a useful domain for studying bias because performance reflects objective knowledge. In work domains, however, performance may reflect both objective knowledge and social perceptions. Consequently, it is possible that the social stigma associated with obesity would influence actual performance at work. In our following studies, we examine emotional and behavioral reactions to obese coworkers.

\section{Study 2}

In Study 2, we extend our investigation in three ways. First, we use stimuli in which we digitally manipulate obesity, rather than relying on text manipulations (pilot study) or natural variations in weight (Study 1). Second, we begin to test Hypothesis 3 by examining how the association between obesity and competence influences harming intentions.

We also investigate how individuals’ own body composition influences their reactions to obesity. Prior research has found that obese individuals exhibit the same weight-based biases as non-obese individuals (e.g., Crandall, 1994). Obese individuals often hold themselves 
accountable for their weight, attribute negative social feedback to their weight (Crocker et al., 1993), and judge obesity as evidence of a personal flaw (Carpenter, Hasin, Allison, \& Faith, 2000). Consequently, we do not expect that participant weight will moderate our results.

\section{Method}

Participants. We recruited one hundred sixty-eight participants (100 women, 68 men; $M_{\text {age }}=23$ years, $S D=4.75 ; M_{\text {work experience }}=4.71$ years, $\left.S D=4.59\right)$ from a city in the northeastern United States to participate in a study in exchange for a \$10 show-up fee.

Design. We randomly assigned participants to one of eight conditions from a 2(Weight: obese vs. non-obese) x 2(Gender) x 2(Stimulus Sampling) between-subjects design.

Procedure and Materials. We seated participants in separate cubicles to complete the study on a computer. We informed participants that they would see a digital resume created by a student and would be asked to rate the student. The purported purpose of the digital resume was to help students attract potential employers.

Obesity manipulation. The digital resumes included a photograph of a job candidate and a brief “About Me” statement. We described each student as an Economics major, with experience in finance and business development.

We manipulated obesity by providing a photograph of an obese or non-obese individual. To create our stimuli, we digitally manipulated the photographs of four different non-obese individuals, two males and two females, so that they appeared obese. We used headshots of former student participants, who consented to having their photographs used for future research. We provide our stimuli and an example of a digitally manipulated photograph in Appendix B. 
Dependent variables. Each participant rated the candidate along three scales to measure competence, behavioral intentions, and appearance. As in the pilot study, we employed indirect measures.

Competence. In Study 2, we used a larger scale to measure competence. In Study 2, we measured eight traits (competent, intelligent, confident, competitive, skillful, efficient, capable, organized; 1 = "Not at all” and 7 = “Extremely”; $\alpha=.94$; Fiske et al., 2002; Cuddy et al., 2007).

Behavioral intentions. Participants rated how much they agreed with the following statements: "Others would [exclude, demean, cooperate with] this student” ( 1 = "Strongly disagree” and 7 = "Strongly agree”). Consistent with prior work, we measured passive harm as the average of intentions to exclude and demean the candidate $(r=.764, p<.001)$, and we measured passive help as intentions to cooperate (Cuddy et al., 2007). ${ }^{4}$

Attractiveness and weight. Participants also rated the candidate’s physical attractiveness along two items: attractive and good-looking $(r=.898, p<.001)$ and weight along two items: overweight and thin (reverse scored) $(r=.736, p<.001 ; 1=$ "Not at all" and $7=$ "Extremely."). After participants submitted their responses, we collected demographic information. At the end of the session, we had participants step on a scale and we recorded their height and weight.

\section{Results}

\footnotetext{
${ }^{4}$ We set out to test Hypothesis 3 by examining the effects of weight on passive harm and passive help. Consequently, we used the same scales that scholars have used to capture these constructs in prior research (Cuddy et al., 2007). However, one limitation of these scales is that there are only 1-2 items per scale.

In Studies 3 and 4, we include items that measure both passive and active behaviors. In these studies, we conducted factor analyses and found evidence of the overarching distinction between help and harm, but we found no differentiation between active and passive behaviors. Thus, we focus on the critical distinction between help and harm and we use expanded scales to measure these constructs in those studies. We thank an anonymous reviewer for this suggestion.
} 
First, we examined if there were any differences between our two female stimuli or between our two male stimuli. For each gender, we found no interactions between our different stimuli and our obesity manipulation on our main dependent variables. Therefore we collapse across stimuli in subsequent analyses and report results from a 2(Weight) x 2(Gender) ANOVA on our dependent variables. Our results are unchanged if we control for stimuli.

Manipulation check. Participants rated candidates in the obese condition as significantly more overweight $(M=5.84, S D=0.77)$ than candidates in the non-obese condition $(M=3.01$, $S D=.91), F(1,164)=523.35, p<.01, \eta_{p}^{2}=.76$. Participants also rated male candidates as more overweight $(M=4.60, S D=0.93)$ than female candidates $(M=4.29, S D=1.82), F(1,164)=$ 6.48, $p=.012, \eta_{p}^{2}=.04$

We also identified a significant Gender $\mathrm{x}$ Weight interaction, $F(1,164)=15.32, p<.01$, $\eta_{p}^{2}=.09$. The obesity manipulation had a greater effect on females' perceived weight $\left(M_{\text {obese }}=\right.$ $5.92, S D_{\text {obese }}=0.71$ vs. $\left.M_{\text {non-obese }}=2.62, S D_{\text {non-obese }}=0.78\right) ; t(84)=19.08, p<.01$, than males' perceived weight $\left(M_{\text {obese }}=5.75, S D_{\text {obese }}=0.83\right.$ vs. $\left.M_{\text {non-obese }}=3.41, S D_{\text {non-obese }}=0.87\right) t(82)=$ 13.14, $p<.01$, although both simple effects were significant. This effect appears to be driven by perceptions of the non-obese females, suggesting that average-weight females are subjectively rated as thinner than average-weight males.

Competence. Supporting our thesis, we found that obese candidates were perceived to be significantly less competent $(M=4.15, S D=1.20)$ than non-obese candidates $(M=4.60, S D$ $=.98), F(1,164)=6.96, p<.01, \eta_{p}^{2}=.04$. We did not find a main effect of Gender, nor did we find a significant Gender x Weight interaction.

Behavioral intentions. We also found that obese candidates were more likely to engender passive harm $(M=4.26, S D=1.23)$ than non-obese candidates $(M=3.31, S D=1.29)$ 
$F(1,164)=23.47, p<.001, \eta_{p}^{2}=.13$, consistent with Hypothesis 3. Obese candidates were also marginally less likely to engender cooperation (passive help) $(M=4.51, S D=1.05)$ than nonobese candidates $(M=4.82, S D=1.05), F(1,164)=3.58, p=.06, \eta_{p}^{2}=.02$. We did not find main effects of Gender or significant Gender x Weight interactions on passive harming or helping intentions.

Mediation analyses. We conducted a bootstrap analysis with 10,000 samples to test whether or not perceived competence mediates the relationship between obesity and passive harm (MacKinnon et al., 2007). We found a significant indirect effect of competence (Indirect Effect $=.18, S E=.07 ; 95 \% C I=[.06, .35])$. Specifically, we found that as weight increased, perceived competence decreased $(a=-0.45, p<.01$ ), and as perceived competence decreased, harming intentions increased $(b=-0.40, p<.01)$. Once we included competence in our model, the effect of weight on passive harming intentions significantly decreased from $c=0.95, p<.01$ to $c^{\prime}=0.77, p<.01$. This provides evidence of partial mediation, but suggests there are other underlying mechanisms that relate obesity to harm.

--- Figure 3 about here ---

\section{Ancillary analyses}

Effect of participants' weight. We conducted exploratory analyses to determine whether participants’ own body compositions influenced their perceptions of obese candidates. Six participants refused to have their height and weight measured and were excluded from this section of the analyses.

We calculated participants’ BMI according to their height and weight. The mean BMI of participants in our sample was 24.80, with standard deviation 5.15. We conducted two linear regressions, one using harming intentions as the dependent variable and one using competence as 
the dependent variable. In both regressions, we used participant BMI, candidate weight, and the participant BMI x candidate weight interaction as independent variables. In both regressions, the BMI x candidate weight interaction was not significant (competence: $b=-0.01, p=.74, R^{2}=.05$; harm: $\left.b=-0.02, p=.54, R^{2}=.14\right)$. That is, consistent with prior research (e.g., Crandall, 1994), we do not find that participant weight differentially influenced perceptions of obese and nonobese candidates.

We also conducted exploratory contrasts, in which we examine the simple effects of candidate weight on competence and harming intensions, across each of the four weight classes identified by the National Institute of Health: Underweight (BMI less than 18.5), Normal weight $(\mathrm{BMI}=18.5-24.9)$, Overweight $(\mathrm{BMI}=25-29.9)$, and Obese (BMI greater than 30). Our analyses reveal that, at least directionally, participants in every weight class exhibit anti-obesity prejudice. Prejudice appears to be particularly strong among underweight participants, although our results are not conclusive, given the small number of underweight participants in our sample. We depict these results in Figure 3.

Controlling for physical attractiveness. We also performed exploratory analyses to disentangle the effects of obesity from physical attractiveness. After entering physical attractiveness as a covariate into our 2(Weight) x 2(Gender) ANOVA, we find a significant effect of obesity on passive harm $\left(F(1,163)=7.14, p<.01, \eta_{p}^{2}=.04\right)$ and we find a marginal effect of obesity on perceived competence $\left(F(1,163)=2.72, p=.10, \eta_{p}^{2}=.02\right)$. Taken together, evidence from our pilot study, Study 1, and Study 2 suggests that interpersonal reactions to obesity do not simply reflect the influence of physical attractiveness on competence.

\section{Discussion}


Obese job candidates were perceived to be less competent than non-obese job candidates. Supporting Hypotheses 3, we find that obese candidates were also targets of passive harming intentions. We find that perceptions of competence partially mediate the relationship between obesity and passive harm. We explore the additional mechanisms that link obesity with harm in Study 3.

In Study 2, we also find that both non-obese and obese individuals have negative perceptions of obese job candidates. Overweight and obese participants also exhibited prejudice towards obese candidates, although not as strongly as underweight participants did. These results suggest, consistent with prior work, that anti-obesity biases are not the result of in-group biases.

\section{Study 3}

In Study 3, we extend our investigation by examining the affective consequences of obesity. We explore the unique role that cognitive perceptions of competence and affective mechanisms play in linking obesity with behavioral responses. We test the prediction that obesity elicits both sympathy and disgust (Hypothesis 2). Additionally, we test a central tenant of the BIAS Map: that affective mechanisms exert greater influence over behavior than do cognitive mechanisms.

\section{Method}

Participants. We recruited two hundred American adults (95 women, 105 men; $M_{\text {age }}=$ 32 years, $S D=11.6 ; M_{\text {work experience }}=12.5$ years, $\left.S D=10.9\right)$ to participate in this study through Amazon Mechanical Turk.

Design. We randomly assigned participants to one of four experimental conditions from a 2(Weight: obese vs. non-obese) x 2(Gender) between-subjects design.

Procedure and materials. In Study 3, participants read information that a (fictitious) potential job candidate had submitted online, and then they evaluated the candidate. Participants 
first read general information about the candidate's height, weight, age, and race, which was identical to the information we provided in the pilot study. However, we wanted to provide more context and potentially competence-relevant information in Study 3 to examine the robustness of our effects. After participants read general information about the candidate, they read a brief statement about the job candidate's career interests and previous experience. The job candidate had experience in finance and business development. We held this information constant across conditions.

Obesity manipulation. We used the same text weight manipulation that we used in the pilot study.

Dependent variables. Each participant rated the job candidate using three scales: competence, affective reactions, and behavioral intentions. We employed indirect measures.

Competence. We used the same five-item competence scale that we used in the pilot study and Study $1(\alpha=.86)$.

Affective reactions. In Study 3, we asked participants to rate the likelihood (1 = "Very unlikely" to 7 = "very likely") that peers and potential coworkers would experience the following emotions in reaction to the candidate: pity, sympathy, and disgust. Consistent with Cuddy et al. 2007, we measured overall sympathy as the average of the items "sympathy" and "pity" ( $r=.66$, $p<.001)^{5}$

\footnotetext{
${ }^{5}$ Participants also judged the likelihood that others would experience admiration, envy, and contempt towards the candidate. Consistent with the BIAS map, obese candidates elicited marginally more contempt $(p=.07)$ and significantly less admiration $(p<.01)$. We found no effects of obesity on envy. We focus on sympathy and disgust in the present research because these were the only emotions related to both weight and behavioral intensions in Study 3 and in related pilot studies.
} 
Behavioral intentions. In Study 3, we measured passive (“cooperate”) and active (“assist”, “help”) intentions to help, as well as passive (“demean”, “exclude”) and active (“fight”, “sabotage”) intentions to harm the candidate. We adapted all of these items from Cuddy et al., (2007); 1 = "Strongly disagree” and 7 = "Strongly agree.”

Although the BIAS map proposes that active (i.e. intentions to assist, help, fight, sabotage) and passive (i.e. intentions to cooperate, demean, exclude) behavioral responses are fundamentally different, we did not find evidence of a distinction between active and passive behaviors in Study 3. We conducted an exploratory factor analysis (Varimax rotation), and found that our behavioral intentions items loaded on two factors, which accounted for $74.3 \%$ of the variance. The first factor (eigenvalue $=3.96$ ) included the three help items and (loadings $\geq|.77|$ ), and the second factor (eigenvalue $=1.24$ ) included the four harm items (loadings $\geq|.62|$ ). Therefore, we focus on the critical distinction between help and harm in our analyses. We combined intentions to cooperate with, help, and assist the candidate into one measure of help ( $\alpha$ $=$.87). We combined intentions to sabotage, fight with, demean, and exclude the candidate into one measure of harm $(\alpha=.85)$.

After participants submitted their responses, they answered questions about their demographics and work experience.

\section{Results}

We conducted a 2(Gender) x 2(Weight) ANOVA on all of our dependent variables.

Competence. Consistent with our findings in Studies 1 and 2, obese job candidates were perceived to be significantly less competent $(M=4.69, S D=0.93)$ than were non-obese candidates $(M=5.04, S D=0.89), F(1,196)=7.37, p<.01, \eta_{p}^{2}=.04$. We did not find a main effect of Gender or a significant Gender x Weight interaction on perceived competence. 
Affective reactions. Obese candidates elicited greater disgust $(M=2.92, S D=1.67)$ than non-obese candidates $(M=1.94, S D=1.20), F(1,196)=23.65, p<.01, \eta_{p}^{2}=.11$. Obese candidates also elicited greater sympathy $(M=3.18, S D=1.55)$ than non-obese candidates $(M=$ 2.49, $S D=1.31), F(1,196)=11.62, p<.01, \eta_{p}^{2}=.06$. Notably, the effect of obesity on disgust was nearly twice the effect of obesity on sympathy. We did not find main effects of Gender or significant Gender x Weight interactions on sympathy or disgust.

Behavioral intentions. Obese candidates were less likely to elicit help $(M=4.93, S D=$ 1.04) than were non-obese candidates $(M=5.55, S D=0.68), F(1,196)=24.49, p<.01, \eta_{p}^{2}$ $=.11$. We did not find a main effect of Gender or significant Gender $\mathrm{x}$ Weight interaction on helping intentions.

Obese candidates were also more likely to be targets of harm $(M=4.07, S D=1.27)$ than were non-obese candidates $(M=2.40, S D=0.99), F(1,196)=18.89, p<.01, \eta_{p}^{2}=.09$. Female candidates $(M=2.96, S D=1.23)$ were also more likely to be targets of harm than male candidates $(M=2.52, S D=1.10), F(1,196)=8.43, p<.01, \eta_{p}^{2}=.04$. We did not find a significant Gender x Weight interaction on harming intentions.

Mediation analyses. A central prediction of the BIAS Map is that emotion predicts behavior better than does cognition (Cuddy et al., 2007). Consistent with this finding, we expected that sympathy and disgust would predict help and harm towards the obese better than competence. Therefore, we conducted two separate mediation analyses to examine the mechanisms (perceived competence vs. affective reactions) that drive helping and harming intentions towards the obese. For each analysis, we ran bootstrap mediation analysis with 10,000 samples (SPSS Process Macro, Hayes, 2013), entering sympathy, disgust, and competence as potential mediators. 
In Model 1, helping intentions was the dependent variable. Results from Model 1 demonstrate that perceived competence and disgust significantly mediate the relationship between obesity and helping intentions (Indirect Effect of perceived competence = -.08, 95\% CI $=[-.18,-.02]$; Indirect Effect of disgust $=-0.13,95 \% C I=[-.30,-.01])$, but sympathy does not (Indirect Effect of sympathy $=-0.05,95 \% C I=[-.19, .03])$. Specifically, as weight increased, perceived competence decreased ( $\left.a_{1}=-0.35, p<.01\right)$, disgust increased $\left(a_{2}=0.98, p<.01\right)$, and sympathy increased $\left(a_{3}=0.69, p<.01\right)$. In turn, helping intentions decreased $\left(b_{1}=.23, p<.001\right.$; $\left.b_{2}=-0.13, p<.001 ; b_{3}=-0.07, p=.12\right)$. Once we included these mechanisms in our model, the effect of weight on helping intentions significantly changed from $c=-0.62, p<.01$ to $c^{\prime}=-0.35$, $p<.01$, suggesting partial mediation.

In Model 2, harming intentions was the dependent variable. Results from Model 2 demonstrate that perceived competence, disgust, and sympathy significantly mediate the relationship between obesity and harming intentions (Indirect Effect of perceived competence = 0.06, 95\% CI $=[.01, .16]$; Indirect Effect of disgust $=0.35,95 \% C I=[.19, .59]$; Indirect Effect of sympathy $=0.12,95 \% C I=[.03, .28])$. As weight increased, perceived competence decreased, disgust increased, and sympathy increased (same $a$ pathways as Model 1). In turn, harming intentions increased $\left(b_{1}=-.17, p=.02 ; b_{2}=0.36, p<.001 ; b_{3}=0.18, p<.01\right)$. Once we included these mechanisms in our model, the effect of weight on harming intentions significantly decreased from $c=0.67, p<.01$ to $c^{\prime}=0.13, p=.30$, suggesting full mediation.

\section{Discussion}

Consistent with our prior studies, participants in Study 3 judged obese job candidates to be less competent than non-obese job candidates. In Study 3, we use a simple text manipulation of obesity. Our manipulation demonstrates that the affective consequences of obesity are not 
merely triggered by the visually displeasing qualities of obese individuals. Simply learning the weight of a job candidate influenced disgust and sympathy, which contributed to intentions to harm the obese.

Our results also provide evidence of the primacy of disgust in predicting harm towards the obese. The indirect effect of disgust on harm was notably large (.35) and an exploratory analysis revealed that this effect was significantly larger than the indirect effect of competence on harm (95\% CI around the difference in effect sizes $=[.11, .54])$. The indirect effect of sympathy did not differ from either disgust or competence on harm. In other words, consistent with the BIAS Map, affect (i.e., disgust) was a stronger determinant of behavior towards the obese than was cognition. In the next study, we explore ways to increase sympathy and mitigate disgust towards the obese.

\section{Study 4}

In Study 4, we explore the differential effects of warmth and weight loss on reactions to obesity. We also use new stimuli: photographs of real obese individuals before and after they lost weight.

Prior work has failed to study individuals’ perceptions of weight loss. Although much research focuses on diet, exercise, and health interventions as the means to overcoming the obesity epidemic (e.g., Charness \& Gneezy, 2009), work on social cognition has not investigated whether weight loss effectively mitigates the stigma associated with obesity.

Although weight loss may be difficult, directing others’ attention to warmth-related traits may be quite easy. However, we note that signaling warmth may have other negative long-term effects, which we discuss further in the general discussion. The purpose of the present investigation is to examine whether increasing perceptions of warmth can curtail stigma 
associated with low competence. That is, individuals may be able to shift their social categorization not only by overcoming the primary bias (i.e. low competence), but also by signaling the non-focal dimension (i.e. warmth). According to the BIAS Map, warmth can increase sympathy, decrease disgust, and consequently, increase helping intentions towards stereotyped groups.

\section{Method}

Participants. We recruited six hundred four American adults (230 women, 371 men, 3 no-response; $M_{\text {age }}=31$ years, $S D=9.25, M_{\text {work experience }}=11$ years, $S D=15.45$ ) to participate in this study through Amazon Mechanical Turk. ${ }^{6}$

Design. We randomly assigned participants to one of sixteen experimental conditions from a 2(Weight Loss: yes vs. no) x 2(Warmth: cold vs. warm) x 2(Gender) x 2(Stimulus Sampling) between-subjects design. All targets in this study were initially described as obese.

Procedure and Materials. In Study 4, we used actual photographs of obese targets, before and after weight-loss. We collected our photographs from the Biggest Loser website (http://www.nbc.com/the-biggest-loser/photos). The Biggest Loser is an American television show in which obese contestants compete to lose weight. Contestants work with personal trainers over 12 weeks and the person who loses the most weight is awarded a cash prize. We identified two males and two females who had successfully lost weight on The Biggest Loser, and who were similar demographically. All materials are available from the authors upon request.

\footnotetext{
${ }^{6}$ For studies 4 and 5, we recruited larger samples based on pilot studies we had conducted. For our warmth manipulations, we expected an effect size between $d=.2$ and .3 , which requires 176 - 394 participants per cell to detect an effect at $80 \%$ power.
} 
In the study, participants read a scenario about a coworker, named Jeff [Jennifer]. Participants learned that Jeff [Jennifer] was obese and saw a photograph of him/her (which was actually a photograph of a Biggest Loser contestant, before weight loss). Participants then learned that they were transferred to a new unit and didn’t see Jeff [Jennifer] until a sales convention the following year. In the Weight Loss condition, participants then read, "You notice that he [she] has lost a considerable amount of weight. Jeff [Jennifer] is now within a healthy weight range.” A photograph of The Biggest Loser contestant, after weight loss, accompanied this description. In the No Weight Loss condition, participants read, "You notice that he [she] looks the same. Jeff [Jennifer] is still obese.” The original photograph of The Biggest Loser contestant, before weight loss, accompanied this description.

In the warm conditions, Jeff [Jennifer] was described as “warm and friendly.” In the cold conditions, Jeff [Jennifer] was described as “cold and unfriendly.”

Dependent variables. Participants rated Jeff [Jennifer] using four scales: warmth, competence, affective reactions, and behavioral intentions. In contrast to Studies 2 and 3, in which we used indirect measures, in Study 4, we used direct measures. We expect both indirect and direct measures to yield similar results. In this case, direct measures may help to ensure we capture responses to obesity, rather than perceived norms.

Consistent with the pilot study, our warmth scale included four traits (sincere, good natured, warm, and tolerant; $\alpha=.97)$. The competence scale we used was identical to the one we used in the pilot study, Study 1 , and Study $3(\alpha=.89)$.

Similar to Study 3, we asked participants to rate the likelihood that they would experience "sympathy” and "disgust” towards the candidate $(1=$ "Very unlikely", 7 = "Very likely.”). 
We also collected similar behavioral intentions measures. Participants rated their agreement $(1=$ "Strongly disagree” and $7=$ "Strongly agree”) with the following statements: "I would [exclude, demean, humiliate, fight with, sabotage, help, assist, cooperate with] this person." ${ }^{7}$ As in Study 3, helping and harming behaviors loaded separately in an exploratory factor analysis (Varimax rotation), which accounted for $68.6 \%$ of the variance, but we did not find evidence of a distinction between passive and active behaviors. The first factor (eigenvalue $=4.50$ ) consisted of the three help items (loadings $\geq|.79|$ ), and the second factor (eigenvalue $=$ 1.53) consisted of the five harm items (loadings $\geq|.57|$ ). Thus, we combined intentions to help, assist, and cooperate with the target into one measure of Helping Intentions $(\alpha=.92)$ and we combined intentions to humiliate, demean, exclude, fight and sabotage the target into one measure of Harming Intentions $(\alpha=.85)$.

After participants submitted their responses, they answered demographic questions.

\section{Results}

First, we examined whether there were any differences between our two female stimuli or between our two male stimuli. Within each gender, we found consistent effects of warmth and weight loss on all dependent variables across both stimuli. Therefore we collapse across stimuli in subsequent analyses. We report results of a 2(Weight loss) x 2(Warmth) x 2(Gender) ANOVA on all our dependent variables. Our results are unchanged if we control for stimuli. We report the means and standard deviations for Study 4 in Table 2.

\section{Warmth and competence}

$$
\text { --- Table } 2 \text { about here --- }
$$

\footnotetext{
${ }^{7}$ We added the item "humiliate" to generate more potential "passive harm" items. We thought that humiliate, demean, and exclude might have loaded separately from fight and sabotage.
} 
Warmth. Consistent with the intent of the manipulation, participants perceived warm coworkers $(M=5.62, S D=0.86)$ to be significantly warmer than cold coworkers $(M=2.78, S D$ $=1.23), F(1,596)=1145.27, p<.001, \eta_{p}^{2}=.66$.

We also found a main effect of losing weight on perceived warmth, $F(1,596)=20.23, p$ $<.001, \eta_{p}^{2}=.03$. Participants perceived coworkers who lost weight $(M=4.36, S D=1.62)$ to be significantly warmer than coworkers who remained obese $(M=4.03, S D=1.89)$. However, this effect was qualified by a significant Weight Loss $x$ Warmth interaction, $F(1,596)=22.73$, $p$ $<.001, \eta_{p}^{2}=.04$. Cold coworkers who lost weight $(M=3.16, S D=1.24)$ were perceived to be warmer than cold coworkers who did lose weight $(M=2.38, S D=1.10), t(302)=7.09, p=$ $<.001$, but there was no difference in warmth between warm coworkers who lost weight $(M=$ $5.61, S D=0.86)$ and warm coworkers who did not lose weight $(M=5.63, S D=0.86), t(300)$ $=.19, p=.85$. In other words, weight loss boosted perceptions of warmth for cold coworkers, but did not enhance perceptions of coworkers who were already known to be warm. We found no main effects or interaction effects of Gender on perceived warmth.

Competence. The warmth manipulation also influenced perceived competence, $F(1,596)$ 63.38, $p<.001, \eta_{p}^{2}=.10$. Participants perceived cold coworkers $(M=4.33, S D=1.12)$ to be less competent than warm coworkers $(M=4.95, S D=1.03)$. That is, warmth signaled competence. As we predicted, losing weight also signaled competence, $F(1,596)=142.77, p<.001, \eta_{p}^{2}=$. 19. Participants perceived coworkers who lost weight $(M=5.11, S D=0.88)$ to be significantly more competent than coworkers who remained obese $(M=4.17, S D=1.15)$. We did not find a significant Weight Loss x Warmth interaction on perceived competence.

Gender also affected perceptions of competence. Women $(M=4.76, S D=1.06)$ were perceived to be more competent than men $(M=4.53, S D=1.17), F(1,596)=8.39, p<.01, \eta_{p}^{2}$ 
$=.01$. However, this effect was qualified by a significant Gender $\mathrm{x}$ Weight Loss interaction, $F(1$, 596) $=5.14, p=.024, \eta_{p}^{2}=.01$. The weight loss manipulation had a greater effect on males’ perceived competence $\left(M_{\text {Weight-Loss }}=5.09, S D_{\text {Weight-Loss }}=0.88\right.$ vs. $M_{\text {No-Weight-Loss }}=3.97, S D_{\text {No- }}$ Weight-Loss $=1.15) ; t(298)=9.91, p<.01$, than females’ perceived competence $\left(M_{\text {Weight-Loss }}=5.12\right.$, $S D_{\text {Weight-Loss }}=0.87$ vs. $\left.M_{\text {No-Weight-Loss }}=4.38, S D_{\text {No-Weight-Loss }}=1.11\right) t(304)=6.91, p<.01$, although both simple effects were significant. We found no other significant interaction effects of Gender.

\section{Affective reactions}

Sympathy. As we predicted, participants felt less sympathy towards cold coworkers $(3.42, S D=1.55)$ than warm coworkers $(M=4.35, S D=1.66), F(1,596)=50.63, p<.001, \eta_{p}^{2}$ $=.08$. Losing weight did not affect sympathy, nor was there a significant Weight Loss $\mathrm{x}$ Warmth interaction. We did not find any effects of Gender on sympathy.

Disgust. Consistent with our predictions, both signaling warmth and losing weight curtailed disgust. Participants felt more disgust towards cold coworkers $(M=3.68, S D=1.63)$ than warm coworkers $(M=2.16, S D=1.32), F(1,596)=180.52, p<.001, \eta_{p}^{2}=.23$. Furthermore, obese coworkers who lost weight $(M=2.46, S D=1.43)$ evoked less disgust than obese coworkers who remained obese $(M=3.40, S D=1.75), F(1,596)=71.23, p<.001, \eta_{p}^{2}$ $=.11$. We did not find a significant Weight Loss $\mathrm{x}$ Warmth interaction.

Gender also influenced disgust, $F(1,596)=4.62, p=.03, \eta_{p}^{2}=.01$; males elicited greater disgust $(M=3.04, S D=1.68)$ than did females $(M=2.81, S D=1.64)$. We found no significant interaction effects of Gender.

\section{Behavioral intentions}


Help. Both signaling warmth and losing weight increased helping intentions. Participants were more likely to help warm coworkers $(M=5.78, S D=0.96)$ than cold coworkers $(M=4.49$, $S D=1.27), F(1,596)=201.65, p<.001, \eta_{p}^{2}=.25$. Additionally, obese coworkers who lost weight $(M=5.28, S D=1.23)$ were more likely to receive help than obese coworkers who remained obese $(M=4.99, S D=1.34), F(1,596)=11.44, p<.001, \eta_{p}^{2}=.02$. We did not find a significant Weight Loss x Warmth interaction, nor did we find any effects of Gender on helping intentions.

Harm. Signaling warmth also decreased harming intentions, $F(1,596)=77.06, p<.001$, $\eta_{p}^{2}=.11$; participants were less likely to harm warm targets $(M=1.56, S D=0.73)$ than cold targets $(M=2.20, S D=1.03)$. Losing weight marginally curtailed harm, $F(1,596)=3.06, p$ $=.08, \eta_{p}^{2}=.01$; participants were marginally less likely to harm obese coworkers who lost weight $(M=1.83, S D=0.93)$ than obese coworkers who remained obese $(M=1.94, S D=0.95)$. We did not find a significant Weight Loss x Warmth interaction. We did not find any effects of Gender on harming intentions.

\section{Mediation Analyses}

We conducted four separate mediation analyses to examine the mechanisms underlying the effects of weight loss and warmth on helping and harming intentions. For each analysis, we ran a bootstrap mediation analysis with 10,000 samples (SPSS Process Macro, Hayes, 2013), entering sympathy, disgust, and competence as potential mediators.

The processes by which weight loss affects behavior towards the obese. In our first two models, we entered Weight Loss as the independent variable, perceived competence, disgust, and sympathy as simultaneous mediators, and Warmth as a covariate. Controlling for Warmth allows 
us to isolate the effects of weight loss on our dependent measures. In model 1, we entered Help as the dependent variable. In model 2 we entered Harm as the dependent variable.

Model 1 demonstrates that perceived competence and disgust significantly mediate the relationship between weight loss and help (Indirect Effect of perceived competence $=0.18,95 \%$ $C I=[.08, .29]$; Indirect Effect of disgust $=0.27,95 \% C I=[.19, .38])$, but sympathy does not (Indirect Effect of sympathy $=-.008,95 \%$ CI $=[-.04, .03])$. As targets lose weight, perceived competence increases $\left(a_{1}=0.93, p<.01\right)$ and disgust decreases $\left(a_{2}=-0.96, p<.01\right)$, but sympathy does not change $\left(a_{3}=-0.06, p=.63\right)$. In turn, helping intentions increase $\left(b_{1}=0.19, p\right.$ $\left.<.01 ; b_{2}=-0.28, p<.01, b_{3}=.13, p<.01\right)$. Once we include these mechanisms in our model, the effect of weight loss on helping intentions significantly decreases from $c=0.29, p<.01$ to $c^{\prime}$ $=-0.14, p=.11$. In other words, perceived competence and disgust fully mediate the effect of weight loss on helping intentions. An exploratory analysis demonstrated that the indirect effects of competence and disgust were both significantly greater than the indirect of sympathy, although they did not differ from each other.

Model 2 demonstrates that only disgust significantly mediates the relationship between weight loss and harm (Indirect Effect of perceived competence $=-0.05,95 \% C I=[-.14, .03]$; Indirect Effect of disgust $=-0.22,95 \% C I=[-.31,-.14]$; Indirect Effect of sympathy $=0.001$, 95\% CI $=[-.004, .02])$. As targets lose weight, perceived competence increases, disgust decreases, and sympathy does not change (same a pathways as Model 1); in turn, harming intentions decrease $\left(b_{1}=-.05, p=.17 ; b_{2}=.23, p<.01, b_{3}=-.02, p=.45\right)$. Once we include these mechanisms in our model, the effect of weight loss on harming intentions changes, from $c$ $=-0.12 p=.07$ to $c^{\prime}=0.14, p=.07$. Although there is no main effect of weight loss on harm, the mediation analysis demonstrates that weight loss does affect harming intentions through disgust. 
There may simply be other, unmeasured mediators that have opposing effects (Zhao, Lynch, \& Chen, 2010).

The processes by which warmth affects behavior towards the obese. In our latter two models, we entered Warmth as the independent variable, perceived competence, disgust, and sympathy as simultaneous mediators, and Weight Loss as a covariate. Controlling for Weight Loss allows us to isolate the effects of warmth on our dependent measures. In Model 3, we entered Help as the dependent variable. In Model 4 we entered Harm as the dependent variable.

Results from Model 3 demonstrate that perceived competence, disgust, and sympathy significantly mediate the relationship between warmth and helping intentions (Indirect Effect of perceived competence $=0.12,95 \% C I=[.05, .21]$; Indirect Effect of disgust $=0.43,95 \% C I=$ $[.31, .58]$; Indirect Effect of sympathy $=0.12,95 \% C I=[.06, .19])$. Signaling warmth increases perceived competence ( $\left.a_{1}=0.63, p<.01\right)$, decreases disgust $\left(a_{2}=-1.53, p<.01\right)$, and increases sympathy $\left(a_{3}=.93, p<.01\right)$. In turn, helping intentions increases $\left(b_{1}=.19, p<.01 ; b_{2}=-0.28\right.$, $\left.p<.01 ; b_{3}=0.13, p<.01\right)$. Once we included these mechanisms in our model, the effect of weight on passive harming intentions significantly decreases from $c=1.23, p<.01$ to $c^{\prime}=0.61$, $p<.01$, suggesting partial mediation. An exploratory analysis demonstrated that the indirect effect of disgust was significantly greater than the indirect of both competence and sympathy. The indirect effects of sympathy and competence did not differ from each other.

Results from Model 4 demonstrate that only disgust mediates the relationship between warmth and harming intentions (Indirect Effect of perceived competence $=-0.03,95 \% C I=$ $[-.09, .02]$; Indirect Effect of disgust $=-0.34,95 \% C I=[-.46,-.23]$; Indirect Effect of sympathy $=$ $-0.01,95 \% C I=[-.06, .03])$. Signaling warmth increases perceived competence, decreases disgust, and increases sympathy (same $a$ pathways as above). In turn, helping intentions 
increases $\left(b_{1}=-.05, p=.17 ; b_{2}=0.22, p<.01 ; b_{3}=-0.02, p=.45\right)$. Once we included these mechanisms in our model, the effect of warmth on passive harming intentions significantly changes from $c=-0.63, p<.01$ to $c^{\prime}=-0.24, p<.01$, suggesting partial mediation. An exploratory analysis demonstrated that the indirect effect of disgust was significantly greater than the indirect effect of both competence and sympathy. The indirect effects of sympathy and competence did not differ from each other.

\section{Discussion}

In Study 4, we test Hypotheses 4 and 5 and examine the effects of weight loss and warmth on reactions to obesity. Consistent with Hypothesis 4, we find that weight loss increases perceptions of competence, lowers disgust, and increases help. Similar to Study 3, however, we did not find a distinction between passive and active behaviors. Weight loss broadly increased help. We find that both cognitive (increased perceptions of competence) and affective (decreased disgust) mechanisms underlie the relationship between weight loss and helping intentions, although our results provide evidence for only partial mediation. Other mechanisms, such as liking, or attraction, may also underlie the relationship between weight loss and helping behavior.

Although weight loss did not have a main effect on harming intentions, weight loss did impact harming intentions through disgust. Our findings suggest that there are additional mechanisms that increase harm towards obese individuals who have lost weight. Given that much of the population is obese, those who successfully lose weight may be met with envy. This idea is also consistent with the predictions of the SCM: increases in perceived competence may shift feelings of contempt and disgust to feelings of envy. Whether weight loss triggers envy or admiration likely depends on warmth. This is an interesting question for future research. 
We also find support for Hypothesis 5. Warmth increased sympathy, lowered disgust, and increased helping intentions towards the obese. Surprisingly, warmth also decreased harming intentions. Although warmth increased sympathy, we found that (decreased) disgust is the primary mechanism that links warmth with behavioral intentions.

Interestingly, warmth and weight loss did not interact. That is, warmth has the same effects for obese targets that have and have not lost weight. We expect that warmth will have similar effects for individuals who have never been obese. Consequently, the prescription of this study is not that obese individuals, in particular, should display warmth, but rather that warmth can help curtail discrimination associated with perceptions of low competence.

Although it is difficult to compare the magnitude of our manipulations for weight loss and warmth, it is worth noting that across every dependent variable, warmth had a larger effect on interpersonal responses than did weight loss. This is true even though participants were presented with actual photographs of individuals before and after weight loss. Interestingly, warmth also had an unpredicted effect on competence. Being interpersonally cold may reflect low social competence, which may have driven this effect. In our next study, we introduce a control condition to disentangle the beneficial effects of warmth from the detrimental effects of coldness.

\section{Study 5}

In our final study, we provide further evidence of the beneficial effects of warmth on reactions to obesity. The purpose of this study is to disentangle the benefits of warmth from the penalties of coldness by introducing a control condition. We also use a subtler warmth manipulation and we do not use photographs for our weight manipulation. This approach ensures that none of our findings in Study 4 were driven by particular stimuli. 


\section{Method}

Participants. We recruited six-hundred working American adults (181 women, 419 men; $M_{\text {age }}=30$ years, $S D=8.77 ; M_{\text {work experience }}=11$ years, $\left.S D=8.80\right)$ to participate in this study through Amazon Mechanical Turk. A total of 24.8\% of participants were managers in their organizations.

Design. We randomly assigned participants to one of six experimental conditions from a 3(Warmth: cold, control, warm) x 2(Gender) between-subjects design. All targets in this study were described as obese.

Procedure and Materials. As in Study 3, we used digital resumes as our stimuli. The digital resumes we used in Study 5 included a description of a job candidate (gender, race, height, and weight), along with information about his or her education and interests. The descriptions of the obese job candidates were identical to the descriptions we used in Study 3. However, in the Cold and Warm conditions, these resumes also included answers to three "Ice Breaker” questions about the candidate’s general interests and hobbies. In our control condition, these questions were omitted.

Warmth manipulation. In Study 5 we manipulated warmth by providing different responses to the "Ice Breakers.” The "Ice Breakers” consisted of three questions:

1. What is your favorite animal?

Warm response: I love dogs, especially beagles.

Cold response: I don't really like animals, especially dogs.

2. What is your pet peeve?

Warm response: People who behave in a selfish way. Cold response: People who are overly peppy. 
3. Describe your ideal day.

Warm response: I would spend time with family and friends and do something outdoors.

Cold response: I would spend time alone and do something outdoors.

Dependent variables. Each participant rated the candidate using four scales: warmth, competence, affective reactions, and helping intentions. As in Study 4, we used direct measures. We measured warmth and competence using the same scales from Study $4(\alpha$ 's $>$.86). As in Study 4, we also asked participants to rate the likelihood that they would experience "sympathy" and “disgust” towards the candidate (1 = "Very unlikely”, 7 = "Very likely.”)

In Study 5, we focus on helping intentions. Specifically, participants indicated their agreement with the following two statements: "I would help this person” and "I would assist this person” (1 = “Strongly disagree,” 7 = “Strongly agree.”), $(r=.91)$. We collected these two items because they reflect active helping intentions, which are most likely to be affected by warmth, according to the SCM and the BIAS Map.

After participants submitted their responses, they answered demographic questions.

Results. We conducted a 3(Warmth) x 2(Gender) ANOVA on all our dependent variables.

Warmth. Our manipulation significantly increased perceptions of warmth, $F(2,594)=$ 245.10, $p<.001, \eta_{p}^{2}=.45$. Participants perceived the warm candidate $(M=5.43, S D=0.81)$ to be warmer than the control candidate $(M=4.81, S D=0.97) ; t(396)=6.66, p<.01$, and the cold candidate $(M=3.39, S D=1.03) ; t(394)=21.43, p<.01$. Participants also perceived the control candidate to be warmer than the cold candidate, $t(407)=15.16, p<.01$. We did not find any main effects or interaction effects of Gender on perceived warmth. 
Competence. As in Study 4, the warmth manipulation also influenced perceptions of competence, $F(2,594)=8.40, p<.001, \eta_{p}^{2}=.03$. Participants perceived the cold candidate $(M=$ 4.32, $S D=0.99)$ to be less competent than the control candidate $(M=4.65, S D=1.07) ; t(407)=$ 3.29, $p<.01$, and the warm candidate $(M=4.71, S D=0.98)$; $t(394)=3.75, p<.01$. That is, the expression of cold traits signaled low competence. Participants did not perceive the warm candidate to be more competent than the control candidate, $t(396)=.53, p=.59$. We did not find any main effects or interaction effects of Gender on perceived competence.

Sympathy. As we predicted, the warmth manipulation significantly influenced sympathy, $F(2,594)=31.32, p<.001, \eta_{p}^{2}=.10$. Participants felt less sympathy towards the cold candidate $(M=3.16, S D=1.31)$ than they did toward the control candidate $(M=4.05, S D=1.49), t(407)=$ 6.26, $p<.01$; and the warm candidate $(M=4.21, S D=1.47)$; $t(394)=7.33, p<.01$. That is, expressing cold traits lowered sympathy towards obese candidates. Participants did not feel more sympathy towards the warm candidate than the control candidate, $t(396)=1.15, p=.25$. We did not find any main effects or interaction effects of Gender on sympathy towards the candidate.

Disgust. The warmth manipulation also significantly influenced disgust, $F(2,594)=$ 54.24, $p<.001, \eta_{p}^{2}=.15$. Participants felt more disgust towards the cold candidate $(M=3.78$, $S D=1.51)$ than they did toward the control candidate $(M=2.67, S D=1.43) ; t(407)=7.89, p$ $<.01$, and the warm candidate $(M=2.37, S D=1.30) ; t(394)=9.84, p<.01$. Participants also felt less disgust towards the warm candidate than they did toward the control candidate, $t(396)=$ 2.06, $p=.04$. This result suggests that obese individuals can curtail disgust by signaling warmth. We did not find any main effects or interaction effects of Gender on disgust towards the candidate. 
Help. The warmth manipulation also significantly influenced helping intentions, $F(2$, $594)=42.56, p<.001, \eta_{p}^{2}=.13$. Participants were less likely to help the cold candidate $(M=$ $4.41, S D=1.27)$ than the control candidate $(M=5.16, S D=1.07), t(407)=6.26, p<.01$; and the warm candidate $(M=5.40, S D=0.95) ; t(394)=8.80, p<.01$. Participants were also more likely to help the warm candidate than the control candidate, $t(396)=2.24, p=.03$. Obese individuals can increase help by exhibiting interpersonal warmth. We display these results in Figure 4 . We did not find any main effects or interaction effects of Gender on helping intentions.

---Figure 4 about here---

Mediation Analyses. We conducted a bootstrap mediation analysis with 10,000 samples (SPSS Process Macro, Hayes, 2013). We entered Warmth as the independent variable, perceived competence, disgust, and sympathy as simultaneous mediators, and Help as the dependent variable.

Results from our analysis replicate our findings from Study 4: perceived competence, disgust, and sympathy together significantly mediate the relationship between warmth and helping intentions (Indirect Effect of perceived competence $=0.07,95 \% C I=[.03, .11]$; Indirect Effect of disgust $=0.16,95 \% C I=[.11, .22]$; Indirect Effect of sympathy $=0.09,95 \% C I=$ $[.06, .13])$. Specifically, we found that as warmth increased, perceived competence and sympathy increased $\left(a_{1}=0.19, p<.01 ; a_{2}=0.53, p<.01\right)$ and disgust decreased $\left(a_{3}=-0.71, p<.01\right)$; in turn, helping intentions increased $\left(b_{1}=0.35, p<.01 ; b_{2}=0.17, p<.01 ; b_{3}=-0.23, p<.01\right)$. Once we include these mechanisms in our model, the effect of warmth on helping intentions significantly changed from $c=0.50, p<.01$ to $c^{\prime}=0.17, p<.01$, suggesting partial mediation. An exploratory analysis demonstrated that the indirect effect of disgust was significantly greater 
than the indirect of both competence and sympathy. The indirect effects of sympathy and competence did not differ from each other.

\section{Discussion}

Study 5 provides further evidence of the beneficial effects of warmth. Consistent with our fifth hypothesis, we find that displaying warmth increases sympathy, decreases disgust, and increases helping intentions towards the obese. Consistent with Study 4, we find that the relationship between warmth and behavior towards the obese operates primarily through (decreased) disgust.

Our results also suggest that the penalties associated with being cold are greater than the benefits associated with being warm. This informs prescriptive advice for both obese and nonobese individuals: signaling interpersonal coldness may make individuals particularly prone to discrimination.

\section{General Discussion}

We investigate obesity with respect to the SCM and BIAS Map and offer a framework to understand and predict behavioral responses to obesity. Using four different manipulations of obesity and both indirect and direct dependent measures, we describe how obesity cues perceptions of low competence, and more broadly, how weight influences fundamental components of social cognition.

These findings expand our understanding of obesity in several ways. We demonstrate that obesity is intricately linked with perceptions of low competence and that this association not only reflects a bias, but also triggers interpersonal reactions that far are more nuanced than prior work has assumed. In contrast to prior research that has linked obesity with broad antipathy (e.g., 
Greenberg et al., 2003; Roehling, 1999), we demonstrate that obesity triggers both negative and positive emotional and behavioral reactions.

We also expand our understanding of weight-based stigma by showing that perceptions other than responsibility for one's condition influence judgments of the obese. Although attribution theory (e.g., Crandall, 1994; King et al., 2006; Teachman et al., 2003) offers insights that are consistent with our findings and the BIAS Map, attribution theory cannot account for the wide range of relationships we identify. For example, by placing obesity within the BIAS MAP framework, we demonstrate that warmth moderates affective and behavioral reactions towards the obese, and that demonstrating warmth may mitigate negative reactions. In fact, in some domains, shifting perceptions of warmth may be as effective as actually losing weight. More broadly, in contrast to prior work, we reveal that stigmatized individuals may be able to shift their social categorization not only by eliminating the source of their stigma, but also by signaling orthogonal, desirable traits.

We also provide new evidence of the primacy of affective mechanisms in predicting reactions to the obese. We demonstrate that disgust, compared to sympathy and perceived competence, is the dominant mechanism that links obesity with both helpful and harmful reactions.

Our experimental strategy also enables us to make important contributions by disentangling constructs that are frequently confounded. First, we demonstrate that the association between obesity and low competence is unjustified. Individuals expect obese targets to perform poorly in competitive settings, but we find no relationship between weight and actual performance. In other words, we document the existence of a bias. 
Second, we disentangle the effects of obesity from the effects of physical attractiveness. We control for physical attractiveness in Study 1, and we use a text-only weight manipulation in our pilot study, Study 3, and Study 5. Results from our text manipulation of obesity reveal that reactions to obesity do not merely reflect visceral reactions to visual stimuli. Rather, by simply reading the information about a person's weight, individuals make inferences about that person's competence and experience specific emotions.

Third, our findings are robust across target and participant gender. Across every study, both male and female targets evoked similar anti-obesity biases, consistent with prior research (e.g., Larkin \& Pines, 1979). In addition, consistent with past research (e.g., Teachman et al., 2003), we also do not find any consistent effects of participant gender on perceptions of the obese.

Furthermore, participants' own weight did not moderate interpersonal perceptions of the obese in our studies. Although our results suggest that underweight participants may be somewhat more discriminatory towards obese individuals than others, we find consistent patterns across all weight classes_-including the heaviest ones. Unlike other types of discrimination such as racial and ethnic discrimination, obese individuals do not favor their in-group. These findings help to explain the prevalence of negative attitudes toward the obese.

\section{Implications and Future Directions}

Obesity is an epidemic in the United States and poses serious challenges to employers and employees. Investigating when and why biases towards the obese are perpetuated in different contexts is important for understanding how to mitigate weight-based discrimination. Our research highlights a number of open areas for future research. 
The SCM and the BIAS Map offer a framework for making a wide set of predictions regarding weight-based discrimination, many of which remain untested. Although prior research has focused almost entirely on the negative emotions that obesity triggers, we find evidence of a potential affective benefit: sympathy. This result suggests that there may actually be some domains in which obese individuals are advantaged. Future research should more closely explore the downstream consequences of sympathy towards the obese.

Although we focus our investigation on sympathy and disgust, these are only two of the four possible affective responses to obesity. According to the SCM, individuals who are perceived to lack competence will also elicit less admiration and envy. We found evidence of low admiration towards the obese in Study 3 (see footnote 5), but we did not fully explore these effects in the present research. If obese targets do not inspire admiration, this may explain why obese individuals receive less credit and recognition, even when they explicitly exhibit competence. Just as increasing the salience of admired and successful Black individuals may help curtail race-based discrimination (e.g. Richeson \& Trawalter, 2005), increasing the salience of admired and successful obese individuals may help curtail weight-based discrimination

It would also be interesting to examine how weight loss affects admiration and envy. In Study 4, we find that although weight loss shifts perceptions of competence, it does not fully mitigate harm. Future work should explore why. For example, it is possible that weight loss may trigger envy from obese observers. The SCM and BIAS Map suggest that warmth, once again, may moderate such emotional responses. Targets who display warmth and who have successfully lost weight may be admired and receive help, whereas targets who display cold traits and who have successfully lost weight may be envied and continue to face discrimination. It is possible that when people observe others lose weight, it reinforces the idea that individuals 
are personally responsible for their weight, and consequently, intensifies biases towards those who remain obese. The specific weight loss strategies that obese individuals pursue (e.g., diet and exercise versus surgical options) may also impact perceptions of obesity, and we call for future work to explore interpersonal perceptions of weight loss.

Future research should also extend our findings by exploring how displaying warmth can curtail stigma, broadly. In Study 5, we introduce a novel tool that researchers can use to manipulate perceived warmth and we find that displays of warmth can activate affiliative emotions towards ambivalent groups (such as the obese). We note, however, that there may be potential pitfalls to prescribing warmth as a solution to social stigma. Although we find that displaying warmth can increase perceptions of competence and lead to positive intergroup behaviors, it is possible that in some circumstances, displaying warmth, rather than dominant behavior, will further subordinate a group. For example, individuals who are perceived to be overly warm may seem naïve and consequently become targets of exploitation. Displaying warmth may also signal that a stigmatized group is satisfied or happy with their social perception, and this may discourage others from taking steps to overcome bias.

Lastly, it is important to understand when obesity influences actual performance versus perceptions of performance. In Study 1, we demonstrate that obesity influenced performance predictions when no actual relationship between weight and performance existed. However, performance at work is likely to reflect both ability and interpersonal interactions. If individuals behave aggressively towards obese employees, or do not invest in their training (Shapiro et al., 2007), obese employees may actually learn less and perform worse over time.

Stereotype work has devoted surprisingly little attention the role of individuals' weight, focusing instead on aspects of individuals such as age, race, gender, and culture. Weight, 
however, is a salient dimension of physical appearance and, as our work demonstrates, significantly influences social perception. Broadly, we encourage scholars to integrate weight into studies of workplace diversity and discrimination. 


\section{Appendix}

Appendix A. Example Stimulus for pilot study - Obese female condition

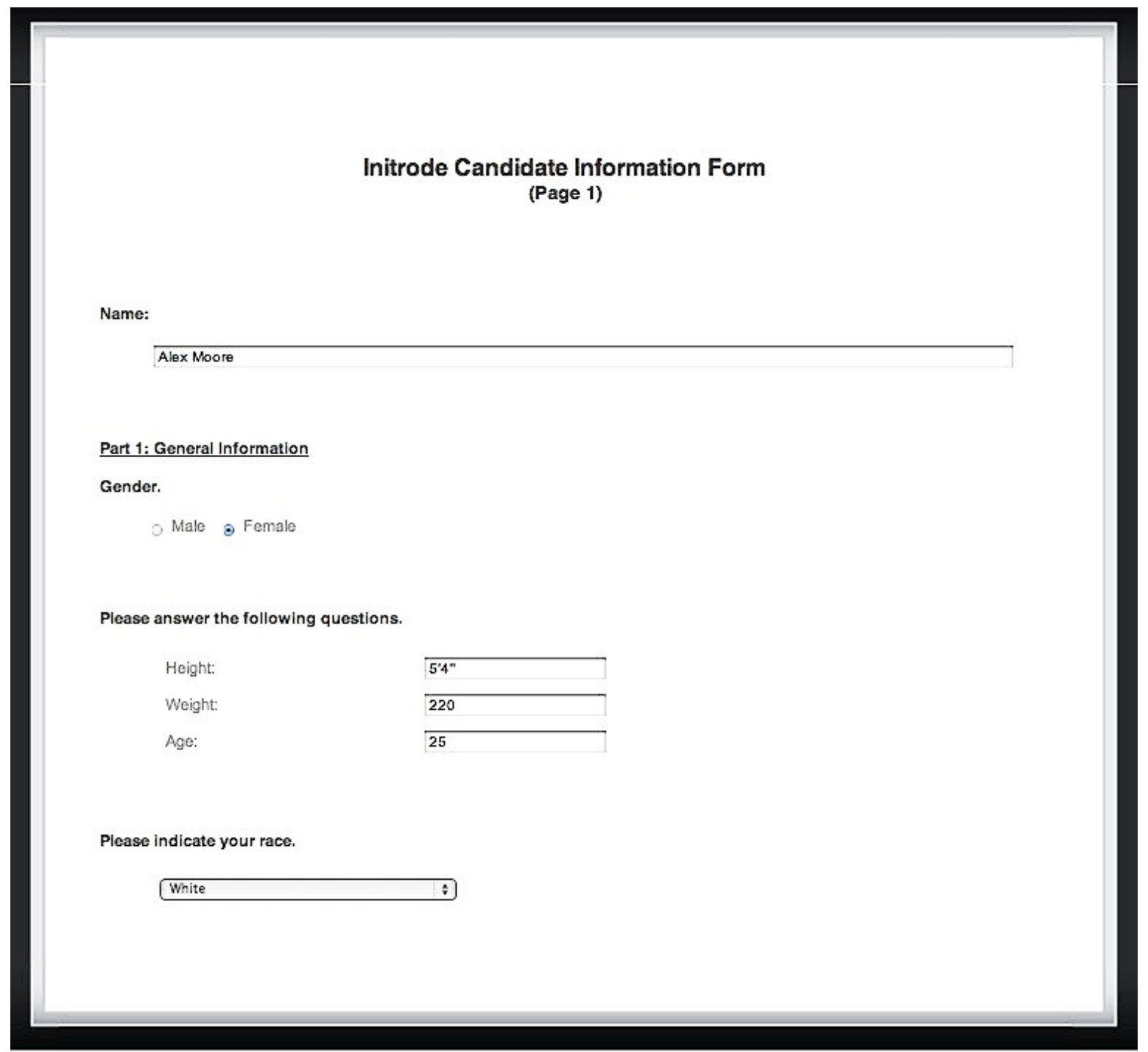

Note. We used the same weight manipulation in Study 3 and Study 5. 
Appendix B. Stimuli in Study 2

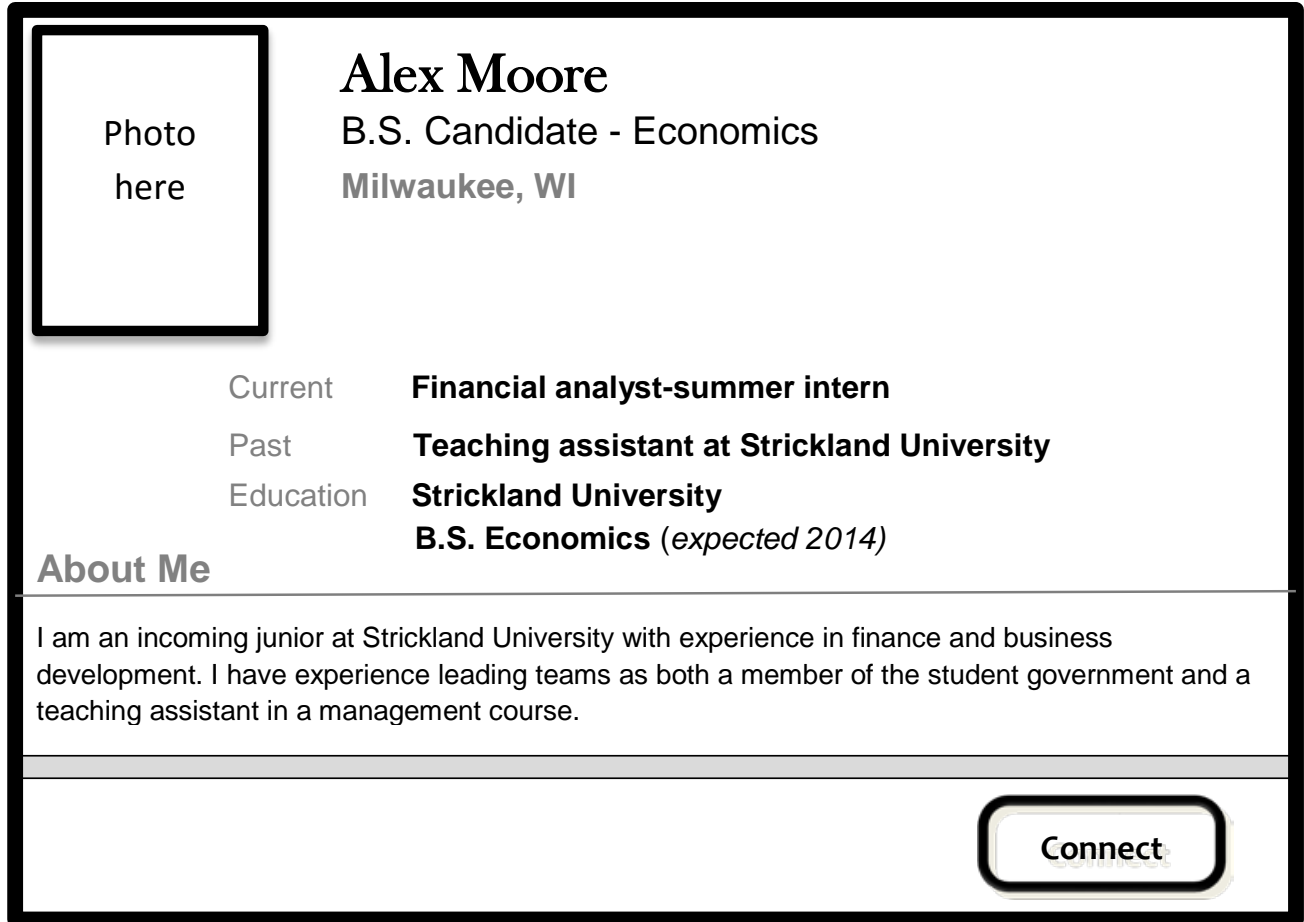

Example photographs depicting digital obesity manipulation:

Original

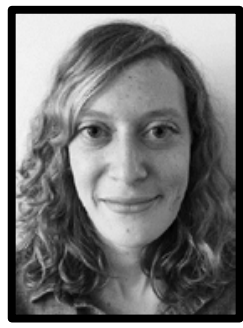

Obesity manipulation

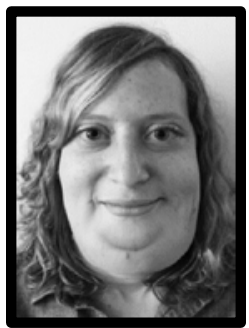

Note. This depicts the digital profile used in Study 2. Below the digital profile, we provide an example of one photograph that was manipulated to appear obese, using the software we used in Study 2. Because we did not have explicit IRB approval to publish the photographs we used in this study, these photographs feature the first author of this paper, rather than the actual stimuli that we used. Full materials are available from the authors upon request. 


\section{References}

Allon, N. (1982). The stigma of overweight in everyday life. In B. B. Woldman (Ed.), Psychological Aspects of Obesity: A handbook (pp. 130-174). New York: Van Nostrand Reinhold.

Allport, G. W. (1954). The Nature of Prejudice. Reading, MA: Addison Wesley.

Baum, C. L., \& Ford, W. F. (2004). The wage effects of obesity: A longitudinal study. Health Economics, 13(9), 885-899.

Bellizzi, J. A., \& Hasty, R. W. (1998). Territory assignment decisions and supervising unethical selling behavior: the effects of obesity and gender as moderated by job-related factors. Journal of Personal Selling \& Sales Management, 18(2), 35-49.

Brewer, M. B. (1979). In-group bias in the minimal intergroup situation: A cognitivemotivational analysis. Psychological Bulletin, 86(2), 307.

Bulik, C. M., Wade, T. D., Heath, A. C., Martin, N. G., Stunkard, A. J., \& Eaves, L. J. (2001). Relating body mass index to figural stimuli: Population-based normative data for Caucasians. Journal of the International Association for the Study of Obesity, 25(10), 1517-1524.

Cahnman, W. J. (1968). The stigma of obesity. The Sociological Quarterly, 9(3), 283-299.

Carpenter, K. M., Hasin, D. S., Allison, D. B., \& Faith, M. S. (2000). Relationships between obesity and DSM-IV major depressive disorder, suicide ideation, and suicide attempts: Results from a general population study. American Journal of Public Health, 90(2), 251257.

Cawley, J., \& Meyehoefer, C. (2012). The medical care costs of obesity: An instrumental variables approach. Journal of Health Economics, 31(1), 219-230.

Charness, G., \& Gneezy, U. (2009). Incentives to exercise. Econometrica,77(3), 909-931.

Chen, F. F., \& Kenrick, D. T. (2002). Repulsion or attraction?: Group membership and assumed attitude similarity. Journal of Personality and Social Psychology, 83(1), 111. 
Clausell, E., \& Fiske, S. T. (2005). When do subgroup parts add up to the stereotypic whole? Mixed stereotype content for gay male subgroups explains overall ratings. Social Cognition, 23(2), 161-181.

Crandall, C. S. (1994). Prejudice against fat people: Ideology and self-interest. Journal of Personality and Social Psychology, 66(5), 882-894.

Crocker, J., Cornwell, B., \& Major, B. (1993). The stigma of overweight: Affective consequences of attributional ambiguity. Journal of Personality and Social Psychology, 64(1), 60-70.

Cuddy, A. J., Fiske, S. T., \& Glick, P. (2004). When professionals become mothers, warmth doesn't cut the ice. Journal of Social Issues, 60(4), 701-718.

Cuddy, A. J., Fiske, S. T., \& Glick, P. (2007). The BIAS map: Behaviors from intergroup affect and stereotypes. Journal of Personality and Social Psychology, 92(4), 631-648.

Cuddy, A. J., Norton, M. I., \& Fiske, S. T. (2005). This old stereotype: The pervasiveness and persistence of the elderly stereotype. Journal of Social Issues, 61(2), 267-285

Dovidio, J. F., Gaertner, S. L., \& Kawakami, K. (2003). Intergroup contact: The past, present, and the future. Group Processes \& Intergroup Relations, 6(1), 5-21.

Eckes, T. (2002). Paternalistic and envious gender stereotypes: Testing predictions from the stereotype content model. Sex Roles, 47(3-4), 99-114.

Fee, H. R., \& Nusbaumer, M. R. (2012). Social Distance and the Formerly Obese: Does the Stigma of Obesity Linger?. Sociological Inquiry, 82(3), 356-377.

Finkelstein, E. A., Ruhm, C. J., \& Kosa, K. M. (2005). Economic causes and consequences of obesity. Annual Review of Public Health, 26(1), 239-257.

Fisher, R. J. (1993). Social desirability bias and the validity of indirect questioning. Journal of Consumer Research, 20(2), 303-315.

Fiske, S. T., Cuddy, A. J. C., Glick, P., \& Xu, J. (2002). A model of (often mixed) stereotype content: Competence and warmth respectively follow from perceived status and competition. Journal of Personality and Social Psychology, 82(6), 878-902. 
Flegal, K. M., Carroll, M. D., Ogden, C. L., \& Curtin, L. R. (2010). Prevalence and trends in obesity among US adults, 1999-2008. JAMA: The Journal of the American Medical Association, 303(3), 235-241.

Glick, P., \& Fiske, S. T. (1996). The Ambivalent Sexism Inventory: Differentiating hostile and benevolent sexism. Journal of Personality and Social Psychology, 70(3), 491.

Goffman, E. (1963). Stigma: Notes on the management of spoiled identity. Englewood Cliffs, NJ: Prentice-Hall.

Greenberg, B. S., Eastin, M., Hofschire, L., Lachlan, K., \& Brownell, K. D. (2003). Portrayals of overweight and obese individuals on commercial television. American Journal of Public Health, 93(8), 1342-1348.

Hayes, A. F. (2013). Introduction to Mediation, Moderation, and Conditional Process Analysis. New York: The Guilford Press.

Jehn, K. A., Northcraft, G. B., \& Neale, M. A. (1999). Why differences make a difference: A field study of diversity, conflict and performance in workgroups. Administrative Science Quarterly, 44(4), 741-763.

Judge, T. A., \& Cable, D. M. (2011). When it comes to pay, do the thin win? The effect of weight on pay for men and women. Journal of Applied Psychology, 96(1), 95-112.

King, E. B., Shapiro, J. R., Hebl, M. R., Singletary, S. L., \& Turner, S. (2006). The stigma of obesity in customer service: a mechanism for remediation and bottom-line consequences of interpersonal discrimination. Journal of Applied Psychology, 91(3), 579.

Larkin, J. C., \& Pines, H. A. (1979). No fat persons need apply: Experimental studies of the overweight stereotype and hiring preference. Work and Occupations, 6(3), 312-327.

Larwood, L., \& Gattiker, U. E. (1985). Rational bias and interorganizational power in the employment of management consultants. Group \& Organization Management, 10(1), 317.

Loyd, D. L., Wang, C. S., Phillips, K. W., \& Lount Jr, R. B. (2013). Social category diversity promotes premeeting elaboration: The role of relationship focus. Organization Science, 24(3), 757-772. 
MacKinnon, D. P., Fairchild, A. J., \& Fritz, M. S. (2007). Mediation analysis. Annual Review of Psychology, 58(1), 593-614.

McKee, K., \& Smouse, A. D. (1983). Clients' Perceptions of Counselor Expertness, Attractiveness and Trustworthiness: Initial Impact of Counselor Status and Weight. Journal of Counseling Psychology, 30(3), 332-38.

Ogden, C. L., Fryar, C. D., Carroll, M. D., \& Flegal, K. M. (2004). Mean Body Weight, Height, and Body Mass Index: United States 1960-2002 (pp. 1-17). Department of Health and Human Services, Centers for Disease Control and Prevention, National Center for Health Statistics.

Pingitore, R., Dugoni, B. L., Tindale, R. S., \& Spring, B. (1994). Bias against overweight job candidates in a simulated employment interview. Journal of Applied Psychology, 79(6), 909-916.

Puhl, R., \& Brownell, K. D. (2012). Bias, discrimination, and obesity. Obesity Research, 9(12), 788-805.

Puhl, R. M., \& Brownell, K. D. (2006). Confronting and coping with weight stigma: An investigation of overweight and obese adults. Obesity, 14(10), 1802-1815.

Quesenberry Jr, C. P., Caan, B., \& Jacobson, A. (1998). Obesity, health services use, and health care costs among members of a health maintenance organization. Archives of Internal Medicine, 158(5), 466-472.

Quinn, D. M., \& Crocker, J. (1999). When ideology hurts: Effects of belief in the Protestant ethic and feeling overweight on the psychological well-being of women. Journal of Personality and Social Psychology, 77(2), 402-414.

Richeson, J. A., \& Trawalter, S. (2005). On the categorization of admired and disliked exemplars of admired and disliked racial groups. Journal of Personality and Social Psychology, 89(4), 517-530.

Roehling, M. V. (1999). Weight-based discrimination in employment: Psychological and legal aspects. Personnel Psychology, 52(4), 969-1016.

Rosette, A. S., Leonardelli, G. J. \& Phillips, K. W. (2008). The White standard: Racial bias in leader categorization. Journal of Applied Psychology, 93, 758-777. 
Rothblum, E. D., Brand, P. A., Miller, C. T., \& Oetjen, H. A. (1990). The relationship between obesity, employment discrimination, and employment-related victimization. Journal of Vocational Behavior, 37(3), 251-266.

Rozin, P., Haidt, J., \& McCauley, C. R. (1993). Disgust. In M. Lewis \& J.M. Haviland (Eds.), Handbook of Emotions (pp. 575-594). New York, NY: Guilford Press.

Rudman, L. A., \& Glick, P. (1999). Feminized management and backlash toward agentic women: The hidden costs to women of a kinder, gentler image of middle managers. Journal of Personality and Social Psychology, 77(5), 1004-1010.

Shapiro, J. R., King, E. B., \& Quinones, M. A. (2007). Expectations of obese trainees: how stigmatized trainee characteristics influence training effectiveness. Journal of Applied Psychology, 92(1), 239.

Sidanius, J., Pratto, F., Van Laar, C., \& Levin, S. (2004). A comprehensive analysis of groupbased oppression: Social dominance theory, its agenda and method. Political Psychology, 25(6), 845-880.

Tajfel, H. (1981). Social stereotypes and social groups. In J. C. Turner \& H. Giles (Eds.), Intergroup Behavior (pp. 144-167). Chicago, IL: University of Chicago Press.

Tajfel, H., \& Turner, J. C. (1979). An integrative theory of intergroup conflict. The Social Psychology of Intergroup Relations, 33, 47.

Teachman, B. A., Gapinski, K. D., Brownell, K. D., Rawlins, M., \& Jeyaram, S. (2003).

Demonstrations of implicit anti-fat bias: The impact of providing causal information and evoking empathy. Health Psychology, 22(1), 68-78.

Vartanian, L. R. (2010). Disgust and perceived control in attitudes toward obese people. International Journal of Obesity, 34(8), 1302-1307.

Weiner, B., Perry, R. P., \& Magnusson, J. (1988). An attributional analysis of reactions to stigmas. Journal of Personality and Social Psychology, 55(5), 738-748.

Wojciszke, B., \& Klusek, B. (1996). Moral and competence-related traits in political perception. Polish Psychological Bulletin, 27, 319-324. 
Zhao, X., Lynch, J. G., \& Chen, Q. (2010). Reconsidering Baron and Kenny: Myths and truths about mediation analysis. Journal of Consumer Research, 37(2), 197-206. 


\section{Tables}

Table 1. The effect of contestant weight on the Predicted Likelihood of Winning a game of Jeopardy! (Study 1).

\begin{tabular}{|c|c|c|c|c|c|}
\hline & $(1)$ & $(2)$ & (3) & (4) & (5) \\
\hline Constant & $\begin{array}{l}.466^{* * *} \\
(0.054)\end{array}$ & $\begin{array}{l}0.452 * * * \\
(0.055)\end{array}$ & $\begin{array}{l}0.449 * * * \\
(0.054)\end{array}$ & $\begin{array}{l}0.516^{* * *} \\
(0.100)\end{array}$ & $\begin{array}{l}0.515^{* * *} \\
(0.091)\end{array}$ \\
\hline Weight & $\begin{array}{l}-0.030^{* *} \\
(0.011)\end{array}$ & $\begin{array}{l}-0.029 * \\
(0.011)\end{array}$ & $\begin{array}{l}-0.028 * \\
(0.011)\end{array}$ & $\begin{array}{l}-0.032 * * \\
(0.012)\end{array}$ & $\begin{array}{l}-0.032 * * \\
(0.012)\end{array}$ \\
\hline Gender & & $\begin{array}{l}0.023 \\
(0.014)\end{array}$ & $\begin{array}{l}0.040 \\
(0.058)\end{array}$ & $\begin{array}{l}0.026 \\
(0.055)\end{array}$ & $\begin{array}{l}0.026 \\
(0.061)\end{array}$ \\
\hline $\begin{array}{r}\text { Weight x } \\
\text { Gender }\end{array}$ & & & $\begin{array}{l}-0.004 \\
(0.012)\end{array}$ & $\begin{array}{l}-0.0007 \\
(0.012)\end{array}$ & $\begin{array}{l}-0.0008 \\
(0.012)\end{array}$ \\
\hline Ictiveness & & & & $\begin{array}{l}-0.011 \\
(0.015)\end{array}$ & $\begin{array}{l}-0.011 \\
(0.011)\end{array}$ \\
\hline $\begin{array}{r}\text { Actual } \\
\text { of Game }\end{array}$ & & & & & $\begin{array}{l}0.003 \\
(0.027)\end{array}$ \\
\hline$d f$ & 298 & 297 & 296 & 295 & 294 \\
\hline $\mathrm{R}^{2}$ & .04 & .05 & .05 & .05 & .05 \\
\hline
\end{tabular}

Note. Dependent variable is the average predicted likelihood of winning a Jeopardy! game. Unit of observation is each contestant (3) in each Jeopardy! game (100). At least 18 participants judged every game. Standard errors are clustered at the game level and the contestant level in every regression.

$* * * p<.001,{ }^{* *} p<.01, * p<.05$. 
Table 2. The effects of weight loss and warmth on interpersonal responses to obesity (Study 4)

Social perception DVs:

\begin{tabular}{|c|c|c|c|c|c|c|}
\hline \multirow[b]{2}{*}{$\begin{array}{l}\text { Weight } \\
\text { Loss }\end{array}$} & \multirow[b]{2}{*}{ Warmth } & \multirow[b]{2}{*}{$\mathrm{N}$} & \multicolumn{2}{|c|}{ Competence } & \multicolumn{2}{|c|}{ Warmth } \\
\hline & & & Mean & $\begin{array}{c}\text { Std. } \\
\text { Deviation }\end{array}$ & Mean & $\begin{array}{c}\text { Std. } \\
\text { Deviation }\end{array}$ \\
\hline \multirow[t]{3}{*}{ No } & Cold & 149 & 3.79 & 1.08 & 2.39 & 1.10 \\
\hline & Warm & 154 & 4.87 & 0.89 & 3.17 & 1.25 \\
\hline & Total & 303 & 4.34 & 1.13 & 2.78 & 1.24 \\
\hline \multirow[t]{3}{*}{ Yes } & Cold & 152 & 4.56 & 1.09 & 5.63 & 0.86 \\
\hline & Warm & 149 & 5.35 & 0.79 & 5.61 & 0.86 \\
\hline & Total & 301 & 4.95 & 1.03 & 5.62 & 0.86 \\
\hline \multirow[t]{3}{*}{ Total } & Cold & 301 & 4.18 & 1.15 & 4.03 & 1.90 \\
\hline & Warm & 303 & 5.11 & 0.88 & 4.37 & 1.63 \\
\hline & Total & 604 & 4.64 & 1.12 & 4.20 & 1.77 \\
\hline
\end{tabular}

Affective Reaction DVs:

\begin{tabular}{|c|c|c|c|c|c|c|}
\hline \multirow[b]{2}{*}{$\begin{array}{l}\text { Weight } \\
\text { Loss }\end{array}$} & \multirow[b]{2}{*}{ Warmth } & \multirow[b]{2}{*}{$\mathrm{N}$} & \multicolumn{2}{|c|}{ Sympathy } & \multicolumn{2}{|c|}{ Disgust } \\
\hline & & & Mean & $\begin{array}{c}\text { Std. } \\
\text { Deviation }\end{array}$ & Mean & $\begin{array}{c}\text { Std. } \\
\text { Deviation }\end{array}$ \\
\hline \multirow[t]{3}{*}{ No } & Cold & 149 & 3.36 & 1.55 & 4.23 & 1.60 \\
\hline & Warm & 154 & 3.48 & 1.55 & 3.14 & 1.48 \\
\hline & Total & 303 & 3.42 & 1.55 & 3.68 & 1.63 \\
\hline \multirow[t]{3}{*}{ Yes } & Cold & 152 & 4.47 & 1.57 & 2.57 & 1.49 \\
\hline & Warm & 149 & 4.22 & 1.74 & 1.74 & 0.95 \\
\hline & Total & 301 & 4.35 & 1.66 & 2.16 & 1.32 \\
\hline \multirow[t]{3}{*}{ Total } & Cold & 301 & 3.92 & 1.66 & 3.40 & 1.75 \\
\hline & Warm & 303 & 3.84 & 1.68 & 2.46 & 1.43 \\
\hline & Total & 604 & 3.88 & 1.67 & 2.92 & 1.67 \\
\hline
\end{tabular}

Behavioral Intention DVs:

\begin{tabular}{|c|c|c|c|c|c|c|}
\hline \multirow[b]{2}{*}{$\begin{array}{l}\text { Weight } \\
\text { Loss }\end{array}$} & \multirow[b]{2}{*}{ Warmth } & \multirow[b]{2}{*}{$\mathrm{N}$} & \multicolumn{2}{|c|}{ Harm } & \multicolumn{2}{|c|}{ Help } \\
\hline & & & Mean & $\begin{array}{c}\text { Std. } \\
\text { Deviation }\end{array}$ & Mean & $\begin{array}{c}\text { Std. } \\
\text { Deviation }\end{array}$ \\
\hline \multirow[t]{3}{*}{ No } & Cold & 149 & 2.29 & 1.02 & 4.30 & 1.28 \\
\hline & Warm & 154 & 2.11 & 1.04 & 4.69 & 1.23 \\
\hline & Total & 303 & 2.20 & 1.03 & 4.50 & 1.27 \\
\hline \multirow[t]{3}{*}{ Yes } & Cold & 152 & 1.60 & 0.75 & 5.68 & 1.01 \\
\hline & Warm & 149 & 1.52 & 0.70 & 5.89 & 0.89 \\
\hline & Total & 301 & 1.56 & 0.73 & 5.78 & 0.96 \\
\hline \multirow[t]{3}{*}{ Total } & Cold & 301 & 1.94 & 0.96 & 4.99 & 1.34 \\
\hline & Warm & 303 & 1.82 & 0.93 & 5.28 & 1.23 \\
\hline & Total & 604 & 1.88 & 0.95 & 5.14 & 1.29 \\
\hline
\end{tabular}


Figures

Figure 1. Hypotheses: Obesity and the BIAS Map.

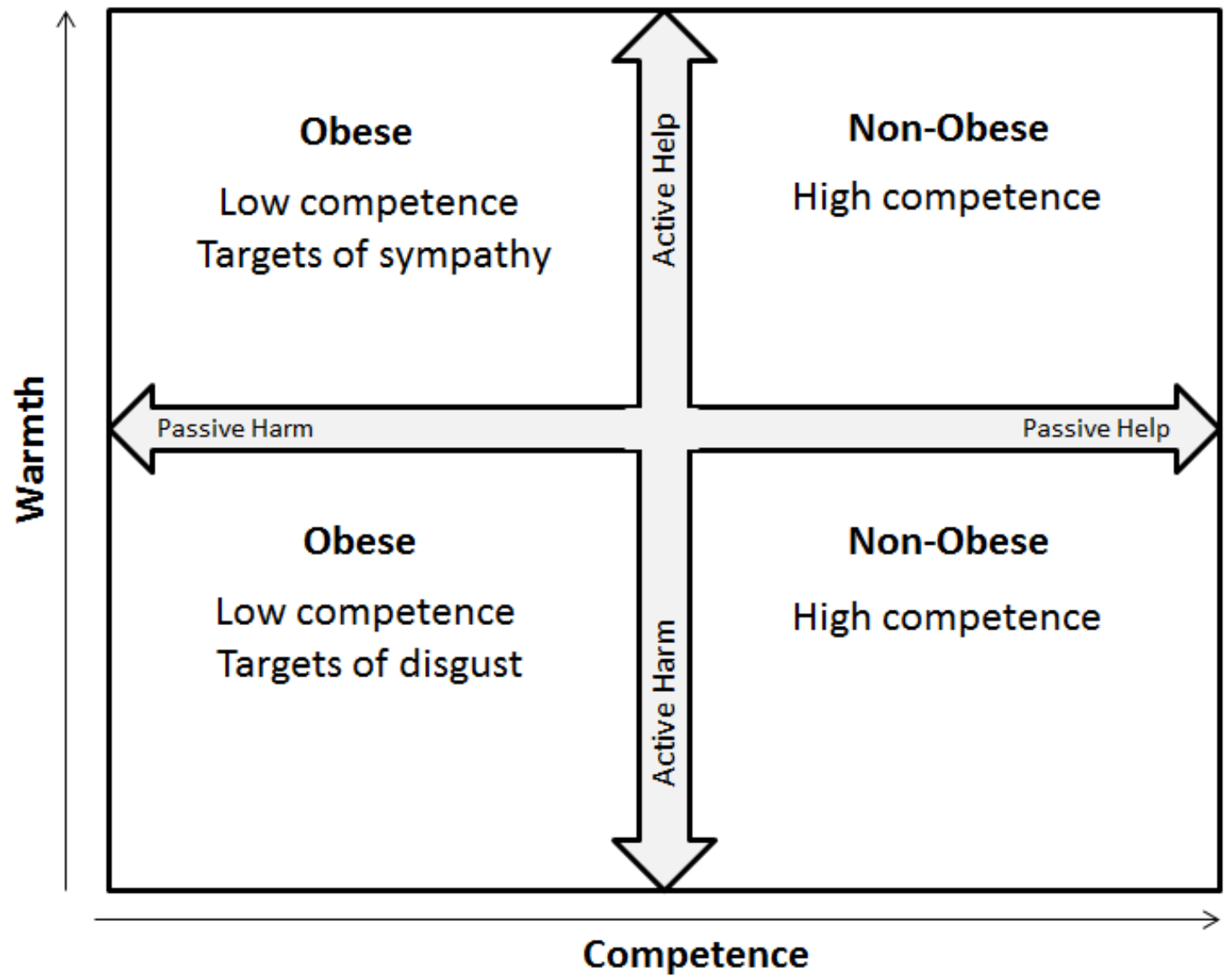


Figure 2. The effect of contestant weight on predicted and actual performance on Jeopardy! (Study 1).

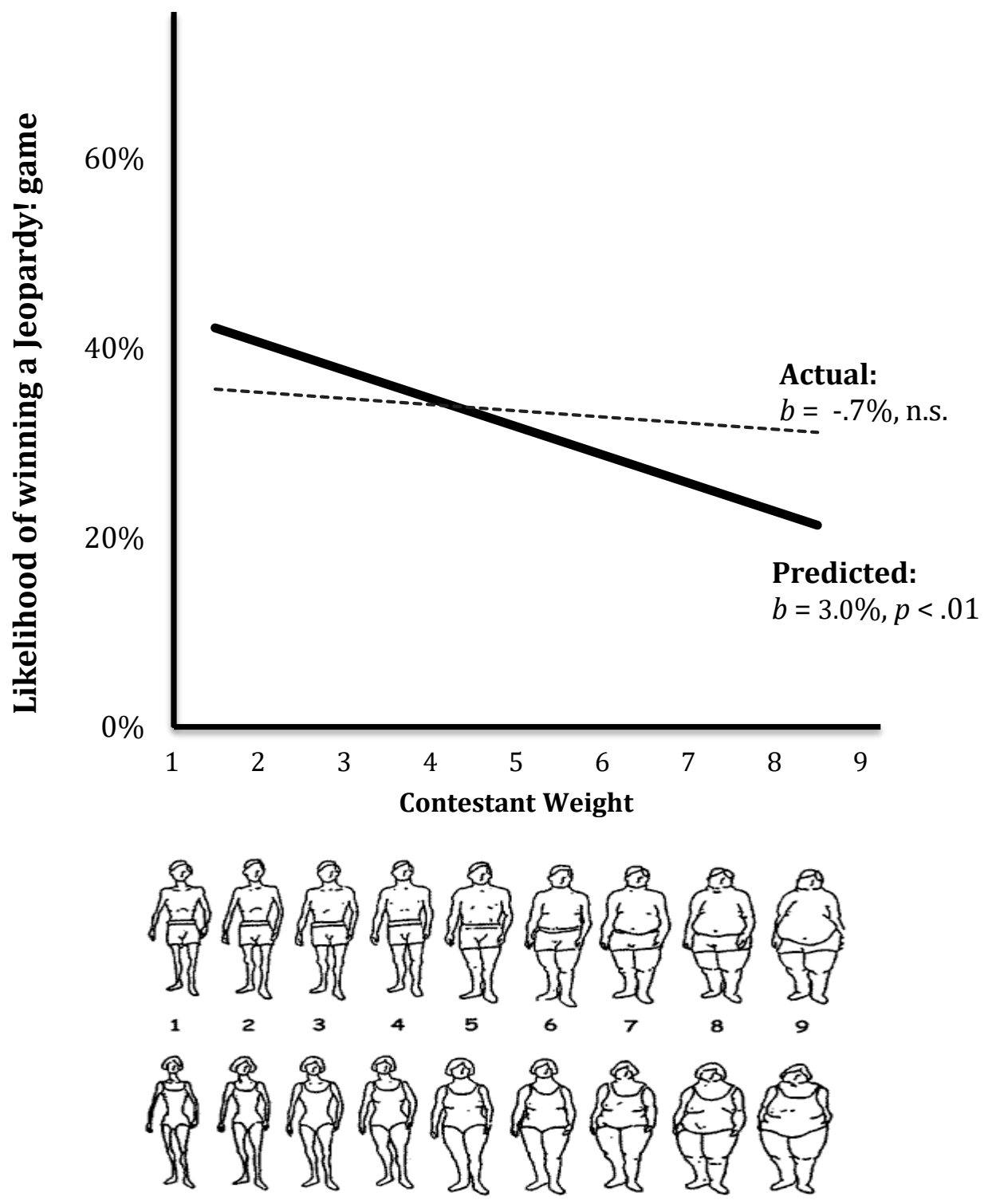

Note. Two independent judges used this BMI scale (Bulik et al., 2001) to code contestants' weight. For ease of comparison, we report the coefficients from linear regressions. 
Figure 3. The effects of obesity on perceived competence and harm, by participant weight class (Study 2).
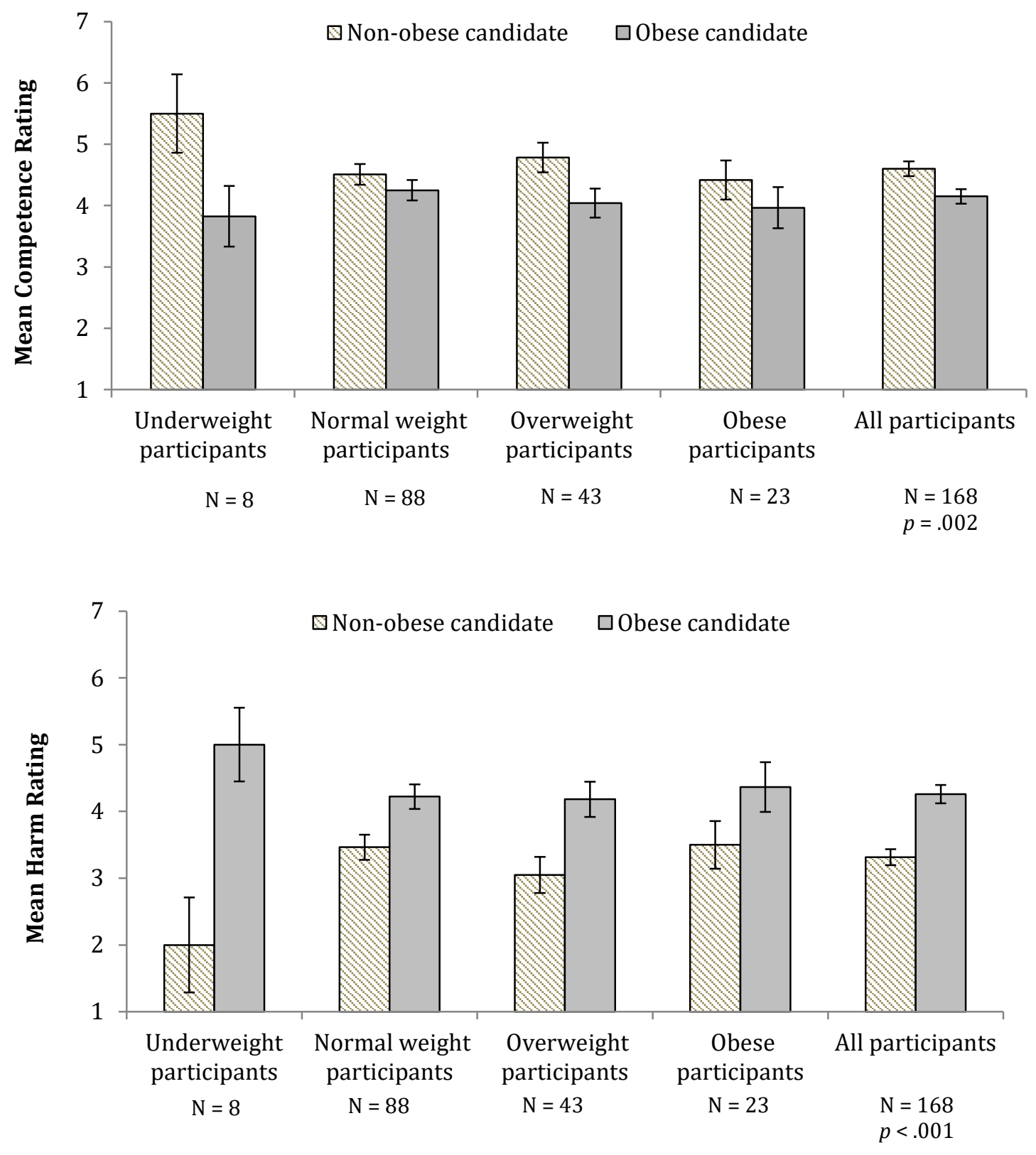

Note. Six participants refused to be weighed in Study 2. “All participants” includes all participants who completed our survey, including the six who were not weighed, and consequently, are not included in one of the four participant weight classes. 
Figure 4. The effects of warmth on sympathy, disgust, and helping towards the obese (Study 5).

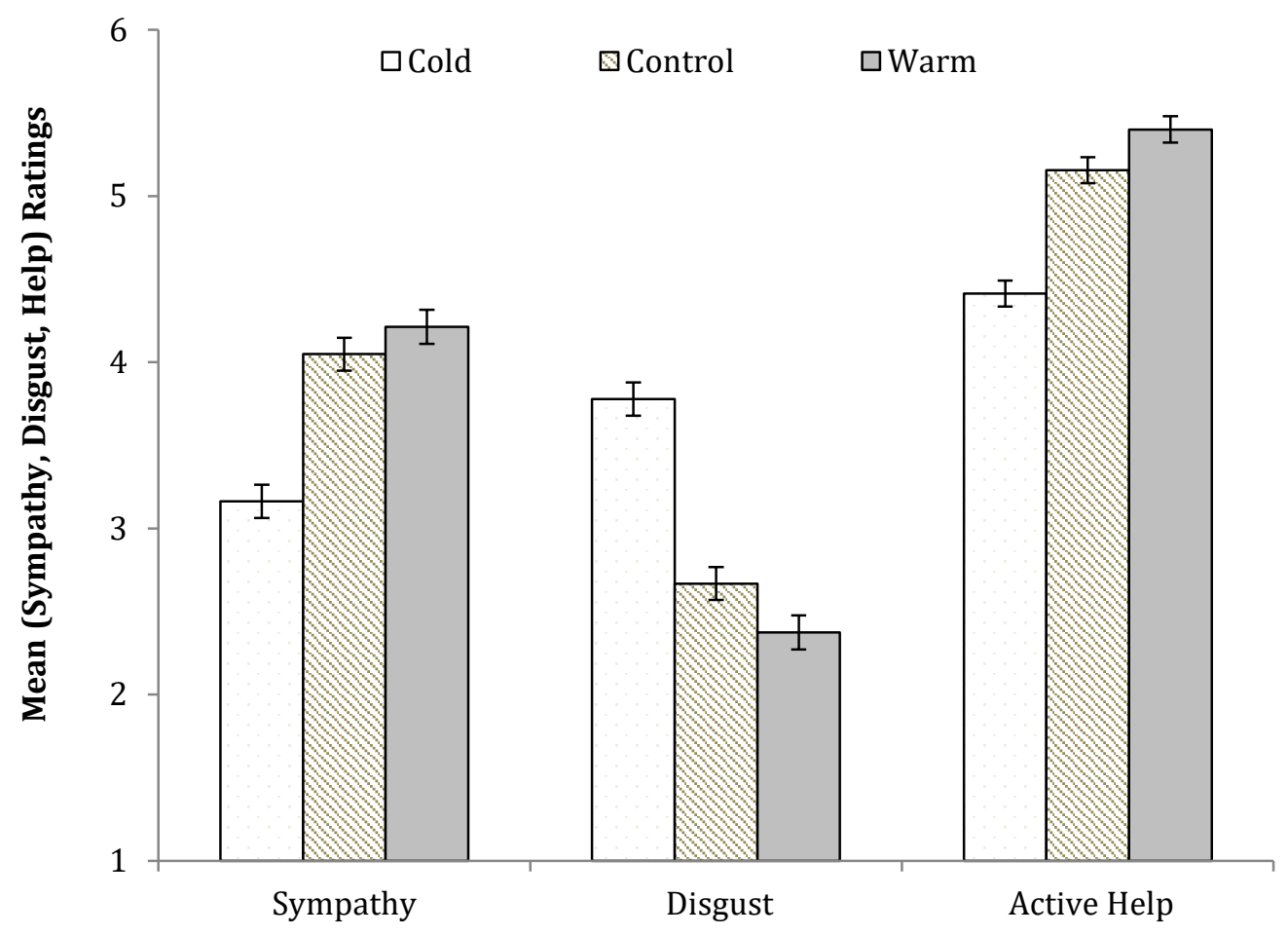

